\title{
RIG-I triggers a signaling-abortive anti-SARS- CoV-2 defense in human lung cells
}

\author{
Taisho Yamada, ${ }^{1,2}$, Seiichi Sato, ${ }^{1,2}$, Yuki Sotoyama ${ }^{1,2}$, Yasuko Orba ${ }^{3,4}$, Hirofumi Sawa ${ }^{3,4,5}$, \\ Hajime Yamauchi', Michihito Sasaki ${ }^{3}{ }^{3}$ and Akinori Takaoka $\mathbb{1}^{1,2} \bowtie$
}

\begin{abstract}
Efficient immune responses against viral infection are determined by sufficient activation of nucleic acid sensor-mediated innate immunity ${ }^{1,2}$. Coronavirus disease 2019, caused by severe acute respiratory syndrome coronavirus 2 (SARS-CoV-2), remains an ongoing global pandemic. It is an urgent challenge to clarify the innate recognition mechanism to control this virus. Here we show that retinoic acid-inducible gene-I (RIG-I) sufficiently restrains SARS-CoV-2 replication in human lung cells in a type $\mathrm{I} / \mathrm{III}$ interferon (IFN)-independent manner. RIG-I recognizes the $3^{\prime}$ untranslated region of the SARS-CoV-2 RNA genome via the helicase domains, but not the C-terminal domain. This new mode of RIG-I recognition does not stimulate its ATPase, thereby aborting the activation of the conventional mitochondrial antiviral-signaling protein-dependent pathways, which is in accordance with lack of cytokine induction. Nevertheless, the interaction of RIG-I with the viral genome directly abrogates viral RNA-dependent RNA polymerase mediation of the first step of replication. Consistently, genetic ablation of RIG-I allows lung cells to produce viral particles that expressed the viral spike protein. By contrast, the anti-SARS-CoV-2 activity was restored by all-trans retinoic acid treatment through upregulation of RIG-I protein expression in primary lung cells derived from patients with chronic obstructive pulmonary disease. Thus, our findings demonstrate the distinctive role of RIG-I as a restraining factor in the early phase of SARS-CoV-2 infection in human lung cells.
\end{abstract}

More than 140 million people around the world have been affected by coronavirus disease 2019 (COVID-19) caused by SARS-CoV-2. COVID-19 varies from mild to severe, life-threatening respiratory infection with coagulopathy. Most (81\%) people infected with SARS-CoV-2 show a mild and self-limited course ${ }^{3}$, while severe cases of disease are more likely to be present in older patients with underlying comorbidities, such as chronic obstructive pulmonary disease $(\mathrm{COPD})^{4-6}$, compared to patients with mild disease. But even young healthy adults sometimes experience severe illness. Conversely, it has been reported that nearly $40-45 \%$ of patients with SARS-CoV-2 infections are asymptomatic ${ }^{7}$. The wide spectrum of clinical manifestations of COVID-19 suggests that individual immune responses to the underlying pathogen may play some crucial role in determining the clinical course. Currently, no efficient therapies and preventive measures exist for COVID-19, thus studies about host immune response against SARS-CoV-2 infection are required for a better understanding of the pathological processes for the rational development of countermeasures to control SARS-CoV-2 infection. There is also an urgent need to identify biomarkers that can predict which patients will deteriorate.

Microbial invasion in our body is sensed by pattern-recognition receptors (PRRs) that are present in most types of cells, which initiate the activation of cell-intrinsic defense and innate immune responses. During RNA virus infection, virus-derived RNA species are mainly targeted by certain subsets of the PRRs. Among such PRRs, RIG-I, melanoma differentiation-associated gene 5 (MDA5) and toll-like receptor 3 (TLR3) play a central role in activation of the downstream signaling pathways, leading to the inductions of type I/III IFNs and proinflammatory cytokines ${ }^{1,2}$. In particular, RIG-I is a critical cytosolic RNA sensor in the detection of a variety of RNA viruses such as influenza $A$ virus $(\mathrm{FluV})^{1,2}$. RNAs carrying a $5^{\prime}$-triphosphate modification (3pRNA) or short-type double-stranded RNAs (dsRNAs), which are found in viral RNA genomes or replication intermediates, are ligands for RIG-I (refs. ${ }^{1,2}$ ). It has been shown that ligand binding to the RIG-I C-terminal domain (CTD) activates the ATPase activity of RIG-I to change its conformation, which enables RIG-I to interact with the adapter protein mitochondrial antiviral-signaling protein (MAVS; also known as IPS-1, VISA or Cardif) through its caspase activation and recruitment domains ${ }^{1,2,8}$. This, in turn, results in kinase-dependent activation of interferon regulatory factor-3 (IRF-3) and nuclear factor kappa B (NF-kB) transcription factors, leading to the activation of the downstream gene induction programs such as type I/III IFN inductions to confer an antiviral state in cells upon viral infection $^{1,2}$. The innate immune mechanism operated by host PRRs during SARS-CoV-2 infection remains poorly understood, although reports suggest that SARS-CoV-2 and its predecessor SARS-CoV have subversion strategies against innate immune signaling through SARS-CoV-2-derived proteins ${ }^{9-12}$.

SARS-CoV-2 is an enveloped, positive-sense, single-stranded RNA betacoronavirus. Entry of SARS-CoV-2 into its target cells such as lung alveolar or bronchial cells is reported to depend on the binding of the viral spike protein to its host angiotensin-converting enzyme 2 (ACE2; ref. ${ }^{13}$ ), in collaboration with two host-cell proteases, TMPRSS2 and ADAM17 (ref. ${ }^{14}$ ). Recent reports have shown that an exacerbated inflammatory response was observed in patients with severe and critical disease ${ }^{15-17}$. On the other hand, no robust upregulation of IFN or other proinflammatory cytokines was observed in the sera of asymptomatic individuals with SARS-CoV-2 infection ${ }^{18}$. In this respect, we hypothesized that there must be some distinctive cell-autonomous innate defense mechanism against

'Division of Signaling in Cancer and Immunology, Institute for Genetic Medicine, Hokkaido University, Sapporo, Japan. ${ }^{2}$ Molecular Medical Biochemistry Unit, Biological Chemistry and Engineering Course, Graduate School of Chemical Sciences and Engineering, Hokkaido University, Sapporo, Japan. ${ }^{3}$ Division of Molecular Pathobiology, Research Center for Zoonosis Control, Hokkaido University, Sapporo, Japan. ${ }^{4}$ International Collaboration Unit, Research Center for Zoonosis Control, Hokkaido University, Sapporo, Japan. ${ }^{5}$ Global Virus Network, Baltimore, MD, USA. 凶e-mail: takaoka@igm.hokudai.ac.jp 
SARS-CoV-2 in these asymptomatic individuals. While there have been accumulating reports of adaptive immune responses against SARS-CoV-2 infection ${ }^{19,20}$, questions regarding the recognition and control of this virus by the innate defense system in lung epithelial cells remain largely unanswered.

We first investigated the innate cytokine responses during SARS-CoV-2 infection in primary human alveolar and bronchial epithelial cells, HPAEpiC and HBEpiC, respectively, and the human lung cancer cell line A549. Although both ACE2 and TMPRSS2 were expressed and sufficient infection was detected in these three cell types (Extended Data Fig. 1a,b), we hardly observed the mRNA induction of IFN- $\beta$, IFN- $\lambda 1$, CXCL10, interleukin (IL)- 6 and tumor necrosis factor (TNF) in response to SARS-CoV-2 infection (Fig. 1a). A similar observation was also obtained in other primary human cells including HBEpC and HCoEpiC (Extended Data Fig. 1c). Consistently, IRF-3 and $\mathrm{I} \kappa \mathrm{B} \alpha$ were not phosphorylated either (Fig. 1b). In addition, the interaction of RIG-I with MAVS was detected upon infection with FluV but not SARS-CoV-2 (Fig. 1c). However, viral replication was suppressed in human cells even without activation of the innate response (Fig. $1 \mathrm{~d}$ and Extended Data Fig. 1d), at least until $24 \mathrm{~h}$ after infection, while innate cytokines were highly induced with prominent viral replication upon FluV infection (Fig. 1a,e). Therefore, we speculated that there might be an unconventional innate defense mechanism to restrict viral propagation.

Because SARS-CoV-2 is an RNA virus, we next examined the involvement of innate RNA sensors in viral suppression in A549 cells. SARS-CoV-2 replication was significantly observed upon knockdown of RIG-I but not MDA5 and TLR3 (Fig. 2a). A similar observation was also obtained in HPAEpiC and HBEpiC cells (Fig. 2b). Consistently, RIG-I deficiency allowed SARS-CoV-2 to replicate after entry into the cell, without any effect on viral infection in both lines of RIG-I knockout (KO) A549 cells (RIG-I KO8 and RIG-I KO35; Fig. 2c and Extended Data Fig. 2a,b). The expression of SARS-CoV-2 spike protein and viral particles was clearly detected in RIG-I KO35 cells but not wild-type (WT) A549 cells (Fig. 2d,e). On the other hand, because RIG-I protein levels were highly decreased in A549 cells that were deficient in the RIG-I adapter MAVS (Extended Data Fig. 3a,b), SARS-CoV-2 replication could also be detected in MAVS KO cells comparably to RIG-I KO cells (Extended Data Fig. 3c). In fact, the re-expression of RIG-I alone in MAVS KO A549 cells restored suppression of viral replication in a dose-dependent manner (Fig. 2f). These data indicate that the underlying mechanism for this viral suppressing activity is based upon RIG-I but not MAVS. Conversely, viral suppression was not restored by the re-expression of MDA5 in MAVS KO cells (Fig. 2f), suggesting that this activity is specific to RIG-I itself.

It has been proposed that COPD is a risk factor for severe COVID-19 that leads to hospitalization and intensive care unit admission $^{4,5,21,22}$. Another interesting report showed that RIG-I expression levels are downregulated in most lung cells derived from patients with $\mathrm{COPD}^{23}$. Consistently, we found that RIG-I expression was barely detected in human primary bronchial epithelial cells (HBEpC-COPD and PBEC-COPD) derived from two independent patients with COPD (Fig. $2 \mathrm{~g}$ ). Of note, viral particles could be detected at $5 \mathrm{~d}$ after infection only in HBEpC-COPD and PBEC-COPD but not healthy donor cells (Fig. 2g). Next, we tried to test the translatability of RIG-I protein upregulation for the control of SARS-CoV-2 infection. RIG-I was first identified as an upregulated gene in the acute promyelocytic leukemia cell line NB4 upon all-trans retinoic acid (ATRA) stimulation ${ }^{24}$, as described by its name. We found that the protein levels of RIG-I could be remarkably upregulated in a dose-dependent manner upon treatment with ATRA in these cells derived from patients with COPD, while ATRA did not affect the protein expressions of ACE2 and TMPRSS2 (Fig. 2h). Treatment with ATRA significantly reduced levels of SARS-CoV-2 viral titers in these cells (Fig. 2i), which was dependent on RIG-I (Extended Data Fig. 3d). These data suggest that RIG-I protein expression is an important parameter that modulates the anti-SARS-CoV-2 innate defense.

Inaccordancewith theseobservations, RNA-immunoprecipitation (RIP) assay, as well as viral cross-linking and solid-phase purification (VIR-CLASP), revealed a specific interaction of RIG-I but not MDA5 with viral RNA in human lung cells after SARS-CoV-2 infection (Fig. 3a and Extended Data Fig. 3f). Further RIP and functional analyses showed that the interaction with viral RNA and viral suppressing activity were detected upon the re-expression of the C-terminal fragment of RIG-I (C-RIG-I) or the helicase domain (HD), but not the CTD in RIG-I KO A549 cells (Fig. 3b,c). In addition, these phenotypes were not affected upon re-expression of RIG-I K270A mutant, which has no ATPase activity ${ }^{26}$, whereas RIG-I Q299A mutant, which lacks dsRNA-binding activity ${ }^{27}$, could not bind to viral RNA with promoted viral replication (Fig. 3d,e). Moreover, the interaction of RIG-I with the SARS-CoV-2 RNA genome failed to stimulate RIG-I ATPase (Fig. 3f), which was also consistent with the observation that SARS-CoV-2 does not activate the conventional RIG-I signaling pathway (Figs. 1b,c and 2f). These results suggest that the RIG-I HD but not the CTD is required for the interaction with SARS-CoV-2 RNA to induce an inhibitory effect on viral replication, without activating the conventional downstream signaling pathways.

We further tried to find the detailed mechanism for how RIG-I exerts a suppressing effect on SARS-CoV-2 replication. SARS-CoV-2 has a positive-sense, single-stranded RNA, which should be transcribed by viral RNA-dependent RNA polymerase (RdRp) into a negative-sense RNA in the first step of viral replication. Therefore, we hypothesized that RIG-I interaction with SARS-CoV-2 may block this RdRp-dependent process. As we expected, any negative-strand RNA was not detected in all the primary human cells tested as well as A549 cells (Fig. 4a,b and Extended Data Fig. 4a), whereas we detected transcribed negative-sense viral RNAs, together with increased levels of positive-sense viral RNAs that were further transcribed from them, in RIG-I KO cells but not IRF-3 KO cells, at $8 \mathrm{~h}$ or later after infection (Fig. 4a and Extended Data Fig. 4b,c). In support of this, positive-sense viral RNA was coprecipitated with RdRp only in the absence of RIG-I (Fig. 4c), which did not affect RdRp protein expression levels (Extended Data Fig. 4d). Recombinant RIG-I (rRIG-I) but not rMDA5 competitively inhibited the binding of RdRp to viral RNA, in a dose-dependent manner (Fig. 4d). We next determined which region(s) of the SARS-CoV-2 RNA genome is responsible for the interaction with RIG-I. The access of the RdRp to the 3'-untranslated region (3' UTR) of the genome, which is conserved in SARS-CoV-2 in terms of RNA secondary structure and sequence ${ }^{28}$, is reported to initiate the negative-strand synthesis

Fig. 1 | SARS-CoV-2 replication is suppressed in human lung cells without activation of innate responses. a, Quantitative PCR with reverse transcription (RT-qPCR) analysis of IFNB1, IFNL1, CXCL10, IL6 or TNF mRNA induction by infection with SARS-CoV-2 (upper) or FluV (lower) in HPAEpiC, HBEpiC or A549 cells ( $n=3$ biologically independent samples). b, Immunoblot analysis of phosphorylated IRF-3 (IRF-3 (p.Ser 396)) and IкB $\alpha\left(I_{\kappa} B \alpha(p . S e r 32)\right.$ ) in A549 cells infected with SARS-CoV-2 or FluV for $0,2,4$ or $8 \mathrm{~h}$. c, Immunoprecipitation (IP) of endogenous MAVS and RIG-I in A549 cells at 0, 2, 4 or $8 \mathrm{~h}$ after infection with SARS-CoV-2 or FluV. d,e, Copy number of SARS-CoV-2 RNA (d) or FluV RNA (e) at 0, 1, 4, 8 or $24 \mathrm{~h}$ after infection with SARS-CoV-2 or FluV in HPAEpiC, HBEpiC or A549 cells ( $n=3$ biologically independent samples). Data are presented as the mean values $\pm s$.d. and are representative of at least two independent experiments with similar results. ND, not detected. RE, relative expression. WCL, whole-cell lysate. 
in other SARS-related betacoronaviruses ${ }^{29,30}$. This prompted us to check whether RIG-I binds to the $3^{\prime}$ UTR of positive-strand SARS-CoV-2 RNA, by using in vitro-transcribed (IVT) $3^{\prime}$ UTR and three other RNA fragments. As expected, rRIG-I protein was preferentially pulled down together with the 3' UTR RNA fragment, as compared to the other IVT RNA fragments (Fig. 4e). To actually a

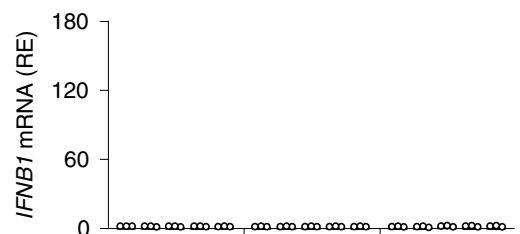

SARS-CoV-2 (h): 014824,014824014824
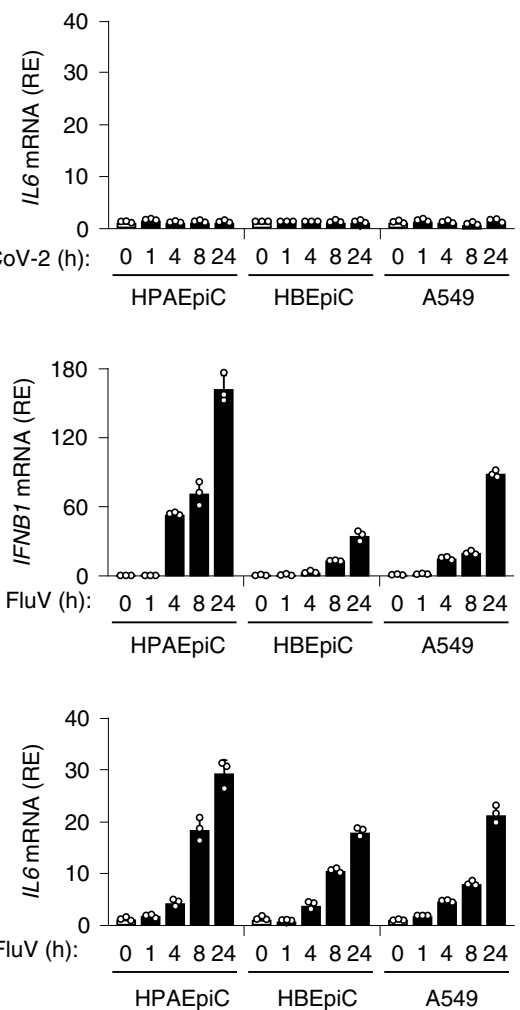

b

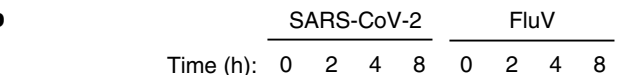
Blot: anti-IRF-3 (pS396)

Blot: anti-IRF-3

Blot: anti-IкB $\alpha(\mathrm{pS} 32)$

Blot: anti-IкB

Blot: anti- $\beta$-actin

d

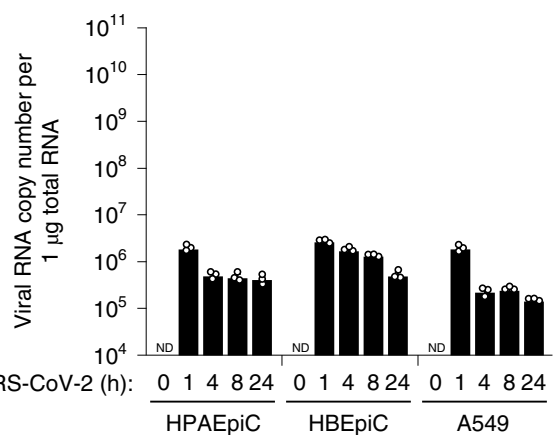

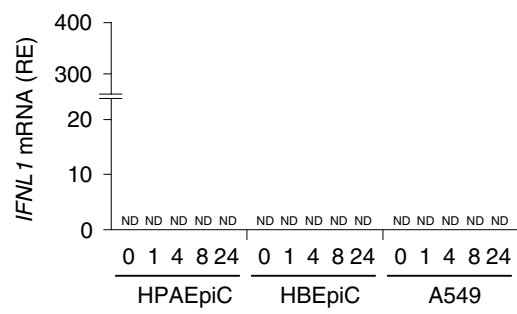
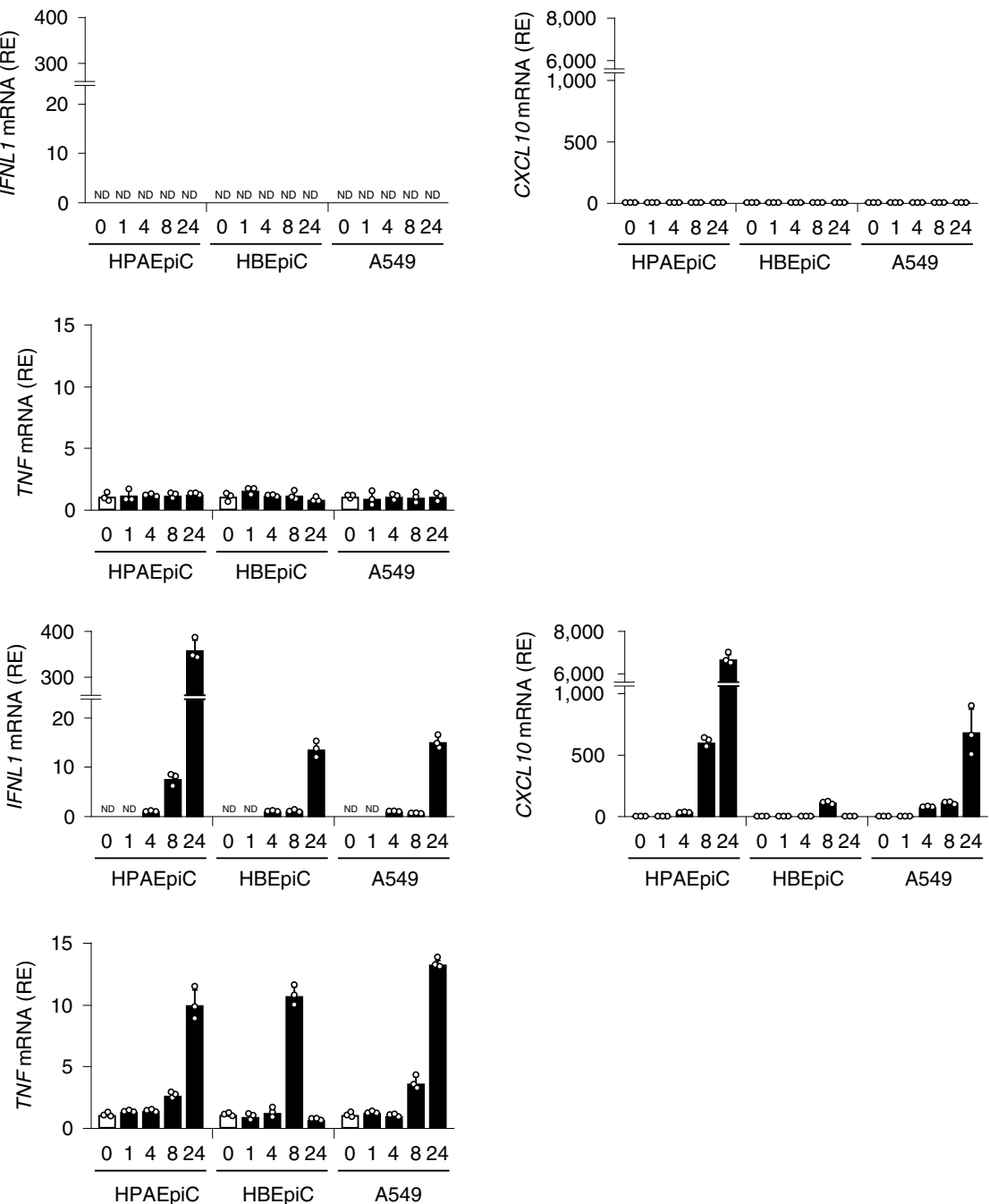

c
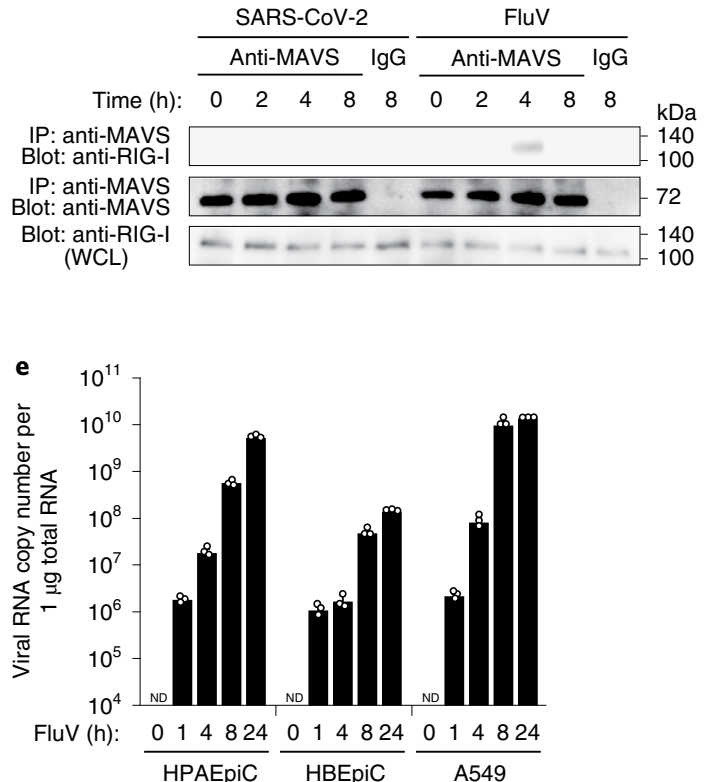
a

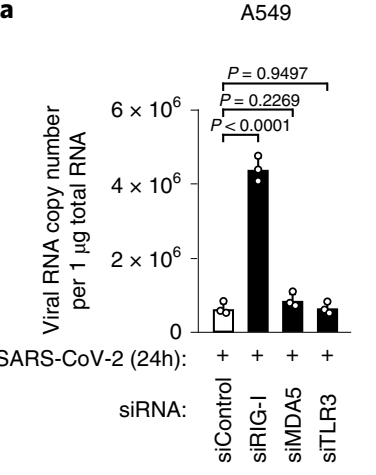

b

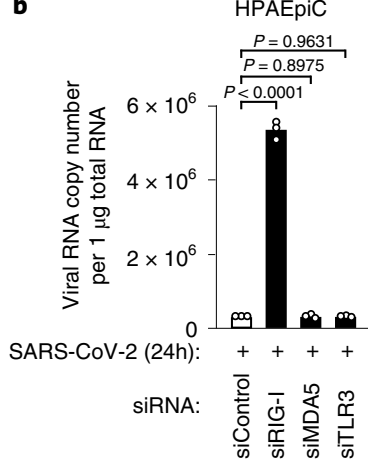

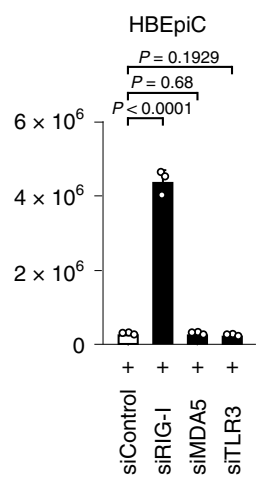

c

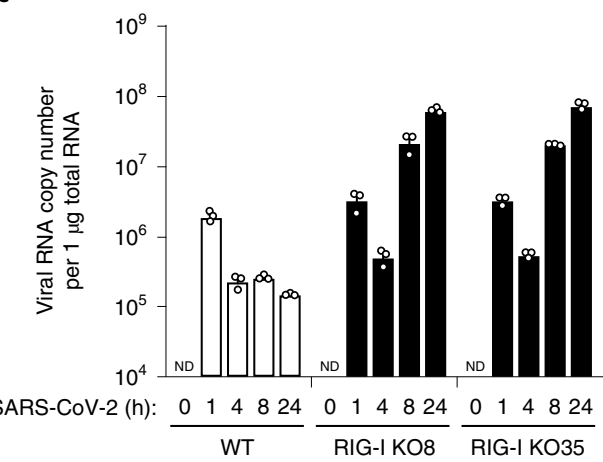

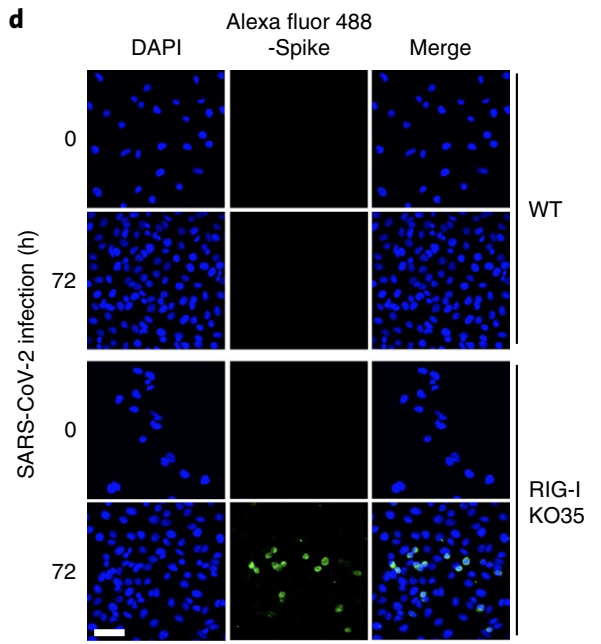

e
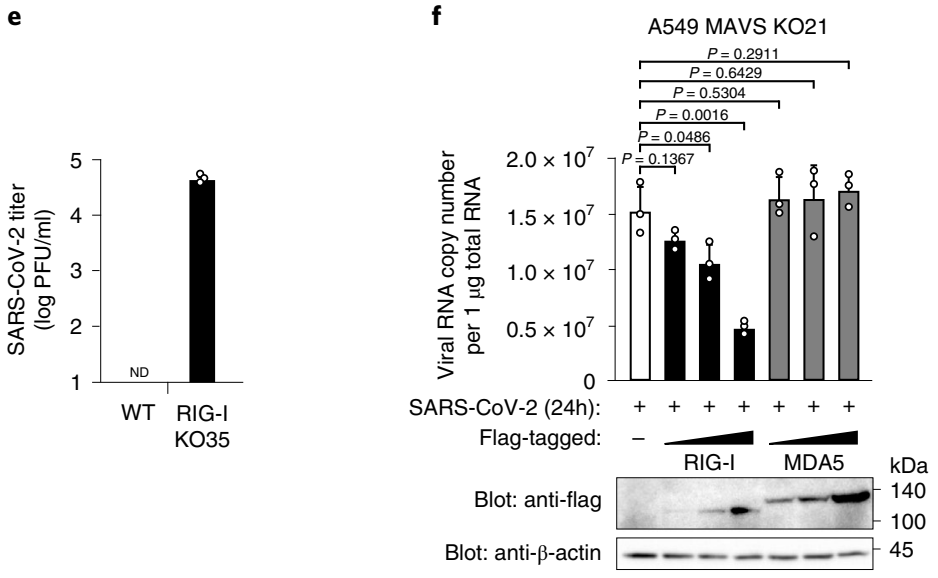

h

i
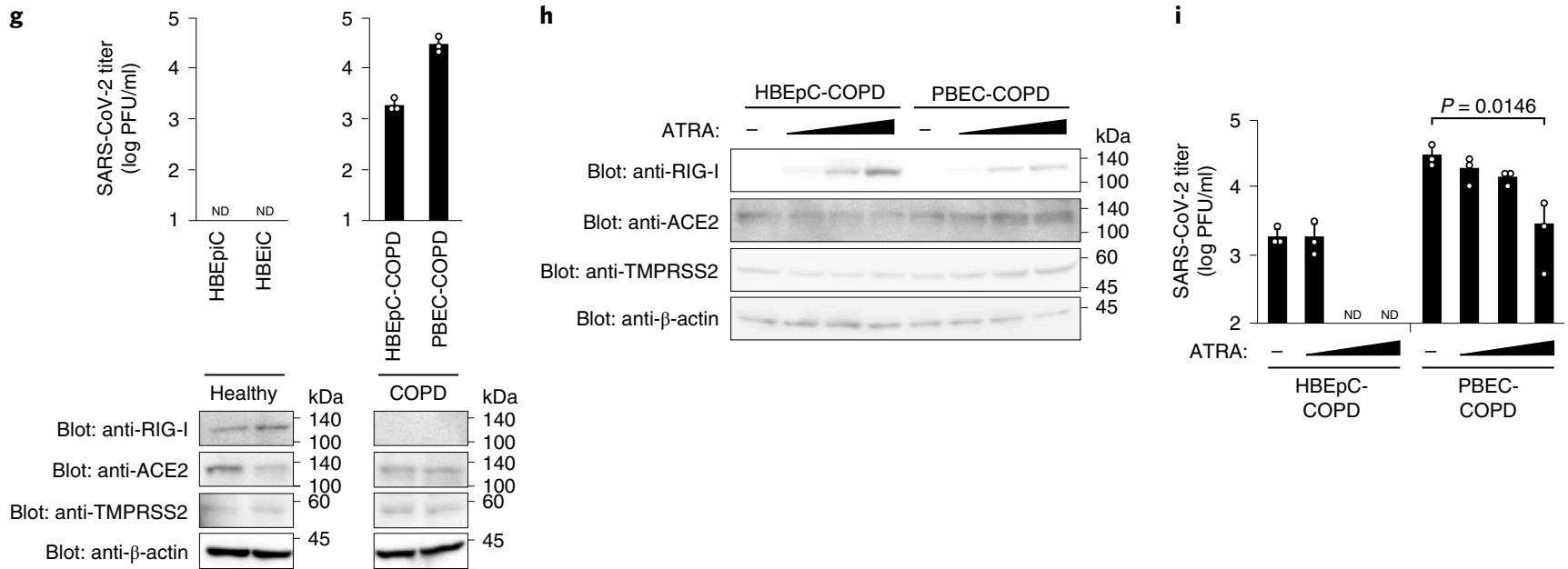

Fig. 2 | RIG-I-mediated suppression of SARS-CoV-2 replication does not require its canonical MAVS-dependent signaling. a,b, Copy number of SARS-CoV-2 RNA at $24 \mathrm{~h}$ after infection with SARS-CoV-2 in A549 (a), HPAEpiC or HBEpiC (b) cells transfected with short interfering RNAs (siRNAs) against gene products of RIG-I (siRIG-I), MDA5 (siMDA5) or TLR3 (siTLR3; $n=3$ biologically independent samples). c, Copy number of SARS-CoV-2 RNA at $0,1,4,8$ or $24 \mathrm{~h}$ after infection with SARS-CoV-2 in A549 WT, RIG-I KO8 or RIG-I KO35 cells ( $n=3$ biologically independent samples). d, Immunostaining of spike protein in A549 WT or RIG-I KO35 cells uninfected or after $72 \mathrm{~h}$ of infection with SARS-CoV-2. Nuclei were counterstained with Hoechst 33342. Scale bar, $50 \mu \mathrm{m}$. e, Viral titers at $5 \mathrm{~d}$ after infection with SARS-CoV-2 in A549 WT or RIG-I KO35 cells ( $n=3$ biologically independent samples). f, Copy number of SARS-CoV-2 RNA at $24 \mathrm{~h}$ after infection with SARS-CoV-2 in A549 MAVS KO21 cells transfected with empty vector (-), Flag-tagged RIG-I or MDA5 expression vector (upper) ( $n=3$ biologically independent samples). Immunoblot analysis of Flag-tagged RIG-I and MDA5 (lower). g, Viral titers at 5 $\mathrm{d}$ after infection with SARS-CoV-2 in HBEpiC, HBEpC, HBEpC-COPD or PBEC-COPD (upper; $n=3$ biologically independent samples). Immunoblot analysis of RIG-I, ACE2 or TMPRSS2 with the lysates of indicated cells (lower). $\mathbf{h}$, Immunoblot analysis of RIG-I, ACE2 or TMPRSS2 with the lysates of indicated cells treated with ATRA $(0,0.01,0.1$ or $1 \mu \mathrm{M})$ for $24 \mathrm{~h}$. i, Viral titers at $5 \mathrm{~d}$ after infection with SARS-CoV-2 in HBEpC-COPD or PBEC-COPD pretreated with ATRA $(0,0.01,0.1$ or $1 \mu \mathrm{M})$ for $24 \mathrm{~h}$ ( $n=3$ biologically independent samples). Data are presented as the mean values $\pm \mathrm{s}$. d. and are representative of at least two independent experiments with similar results. Statistical significance was determined by two-tailed Student's $t$-test. PFU, plaque-forming unit. 
show the interaction of endogenous RIG-I with the 3' UTR region of the viral genome, we performed two different experiments. The interaction of endogenous RIG-I with SARS-CoV-2 genome during infection in primary lung cells as well as A549 cells was selectively suppressed in the presence of the 3' UTR IVT RNA but not the other IVT RNAs (Extended Data Fig. 4e). Consistently, RNase H protection was detected preferentially in the presence of the oligonucleotides targeting the $3^{\prime}$ UTR (P5, PK1, PK2, s2m and Oct; Fig. 4f). These results indicate that endogenous RIG-I detects SARS-CoV-2 through the interaction of its HD with the $3^{\prime}$ UTR of positive-strand viral RNA, which blocks the access of RdRp to viral RNA, shutting off SARS-CoV-2 replication.

In this study, we identified RIG-I as an innate sensor for SARS-CoV-2 in primary human pulmonary epithelial cells. RIG-I recognizes the $3^{\prime}$ UTR of the viral RNA genome in a CTDindependent manner, but this hitherto unknown recognition misfires the activation of the downstream antiviral innate immune signaling, such as the induction of type I/III IFNs and proinflammatory cytokines, which could be explained by the finding that RIG-I ATPase is not stimulated by the interaction with the SARS-CoV-2 RNA genome. However, it is noted that this RIG-I-mediated sensing is sufficient to finally suppress viral propagation after entry into the cell, in an IFN-independent manner. Mechanistically, RIG-I directly exerts its antiviral activity via its competitive inhibition of the recruitment of viral RdRp to viral genome, which blocks the first step of the RdRp-dependent transcription process. In support of this, SARS-CoV-2 replication was detectable upon RIG-I deficiency or downregulation.

Deletion of RIG-I but not MDA5 also allowed primary lung cells and A549 cells to induce innate cytokines (IFNB1, IFNL1 and IL-6) and viral replication upon SARS-CoV-2 infection (Extended Data Fig. 5a-f). Such cytokine inductions observed in RIG-I KO A549 cells or RIG-I knockdown of primary lung cells were significantly suppressed by MDA5 knockdown (Extended Data Fig. 5d,g), which was associated with enhanced viral replication (Extended Data Fig. $5 \mathrm{f}, \mathrm{h})$. In relation to this, it was reported by Yin et al. that SARS-CoV2 -induced innate immune response is dependent on MDA5 in human lung adenocarcinoma cell line Calu- 3 cells $^{31}$, which was consistent with our results using Calu-3 cells (Extended Data Fig. 6a,b). In this respect, we speculated that the reason why we see no IFN and cytokine induction in the primary cells and A549 cells (whereas innate cytokines are induced in Calu-3 cells) may be possibly because of the different expression levels of RIG-I protein. In fact, the levels of RIG-I protein in these cells used in our study were much higher (about ten times) than those in Calu-3 cells (Extended Data Fig. 6c). Our data suggest that in the primary lung cells and A549 cells that have sufficient levels of RIG-I protein, viral replication is blocked by the RIG-I-mediated signaling-abortive anti-SARS-CoV-2 defense mechanism (Fig. 1). On the other hand, SARS-CoV-2 can replicate with innate cytokine induction in cells with low levels of RIG-I expression, including lung cells derived from patients with COPD (Fig. 2g), as observed in Calu-3 cells ${ }^{31}$ (Extended Data Fig. 6a,b). Consistent with this, knockdown-based suppression of RIG-I protein expression resulted in a dose-dependent upregulation of IFN- $\beta$ mRNA induction and viral replication upon SARS-CoV-2 infection (Extended Data Fig. 6d). Exogenous expression of the RIG-I HD but not the CTD in Calu-3 cells suppressed IFN- $\beta$ mRNA induction and viral replication in a dose-dependent manner (Extended Data Fig. 6e). Therefore, it is likely that RIG-I but not MDA5 triggers a signaling-abortive anti-SARS-CoV-2 defense in primary lung cells with sufficient expression of RIG-I, and that in some cells with downregulated RIG-I expression or possibly stability, SARS-CoV-2 can propagate to induce MDA5-dependent innate cytokine responses.

The distinct usage of RIG-I and MDA5 as innate sensors against SARS-CoV-2 appears to depend on the progression of viral replication. We observed the preferential interaction of RIG-I with the positive-strand RNA in the A549 and primary lung cells (Fig. 3a). In contrast, MDA5 preferentially interacts with the negative-strand RNA of the SARS-CoV-2 RNA genome but not the positive-strand RNA (Extended Data Fig. 7a,b). Based on these findings, the possible scenario is that, in the first step, RIG-I recognizes the positive-strand RNA, which was released from viral particles, and blocks viral polymerase-mediated transcription of negative-strand RNA, and in the situation where negative-strand RNA initiates to be transcribed by using the positive-strand RNA as a template, MDA5 in turn plays a role as an innate sensor to induce type I IFNs and other cytokines. This switch seems to be regulated at least partly by the expression levels of RIG-I protein in infected cells.

The current data regarding mechanistic insights also remind us of our previous finding that RIG-I plays a dual role as a hepatitis B virus (HBV) sensor not only to activate antiviral innate signaling but also to inhibit HBV replication in human hepatocytes, wherein RIG-I functions as an antiviral factor that counteracts viral polymerase, in an IFN-independent manner ${ }^{1,32}$. A similar observation was also reported by other groups in the case of FluV infection: The binding of RIG-I to FluV nucleocapsids can directly restrict viral infection in an innate signaling-independent and IFN-independent manner ${ }^{33,34}$. These reports indicate that RIG-I recognizes viral RNAs through the CTD and doubly functions both as an innate immune activator and as a direct antiviral effector at least during $\mathrm{HBV}$ and FluV infection. In the case of SARS-CoV-2 infection, RIG-I-mediated interaction with viral RNA does not seem to trigger the switch in both operational modes. Our data revealed that the

Fig. 3 | The dsRNA-binding activity of RIG-I HD is required for SARS-CoV-2 suppression in a MAVS-independent manner. a, RIP assay with HPAEpiC, HBEpiC or A549 cell lysates prepared after $6 \mathrm{~h}$ of infection with SARS-CoV-2 by using anti-RIG-I, anti-MDA5 or control immunoglobulin. Immunoprecipitated SARS-CoV-2 positive-strand RNA was quantified by RT-qPCR and is represented as fraction of input RNA before immunoprecipitation (percentage of input; upper; $n=3$ biologically independent samples). Immunoblot analysis of whole-cell lysate and immunoprecipitated RIG-I and MDA5 (lower). In addition, encephalomyocarditis virus (EMCV)-derived RNA was specifically detected in MDA5 immunoprecipitates but not RIG-I immunoprecipitates, which were derived from EMCV-infected A549 cells (Extended Data Fig. 3e), as previously reported ${ }^{25}$. b, RIP assay with A549 RIG-I KO35 cell lysates expressing Flag-tagged deletion mutants of RIG-I prepared after $6 \mathrm{~h}$ of infection with SARS-CoV-2 by using anti-Flag antibody. The immunoprecipitated SARS-CoV-2 positive-strand RNA was measured by RT-qPCR as described in a (upper; $n=3$ biologically independent samples). Immunoblot analysis of immunoprecipitated Flag-tagged proteins (lower). c, Copy number of SARS-CoV-2 RNA at $24 \mathrm{~h}$ after infection with SARS-CoV-2 in A549 RIG-I KO35 cells expressing Flag-tagged deletion mutants of RIG-I (upper; $n=3$ biologically independent samples). Immunoblot analysis of Flag-tagged deletion mutants of RIG-I (lower). d, RIP assay with A549 MAVS KO21 cell lysates expressing Flag-tagged point mutants of RIG-I prepared as described in $\mathbf{b}$. The immunoprecipitated SARS-CoV-2 positive-strand RNA was measured by RT-qPCR as described in $\mathbf{a}$ and $\mathbf{b}$ (upper; $n=3$ biologically independent samples). Immunoblot analysis of immunoprecipitated Flag-tagged proteins (lower). e, Copy number of SARS-CoV-2 RNA at $24 \mathrm{~h}$ after infection with SARS-CoV-2 in A549 MAVS KO21 cells expressing Flag-tagged point mutants of RIG-I (upper; $n=3$ biologically independent samples). Immunoblot analysis of Flag-tagged point mutants of RIG-I (lower). f, ATPase activity of recombinant RIG-I protein after the addition of SARS-CoV-2 RNA genome or 3pRNA ( $n=3$ biologically independent samples). Data are presented as the mean values \pm s.d. and are representative of at least two independent experiments with similar results. Statistical significance was determined by two-tailed Student's $t$-test. 
a

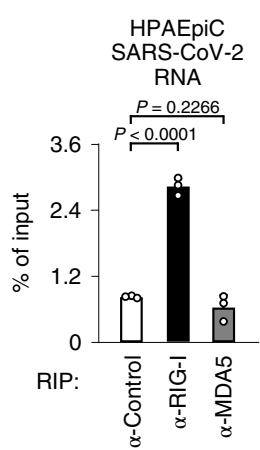

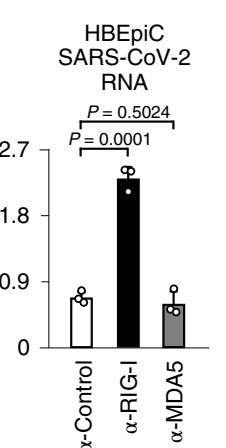
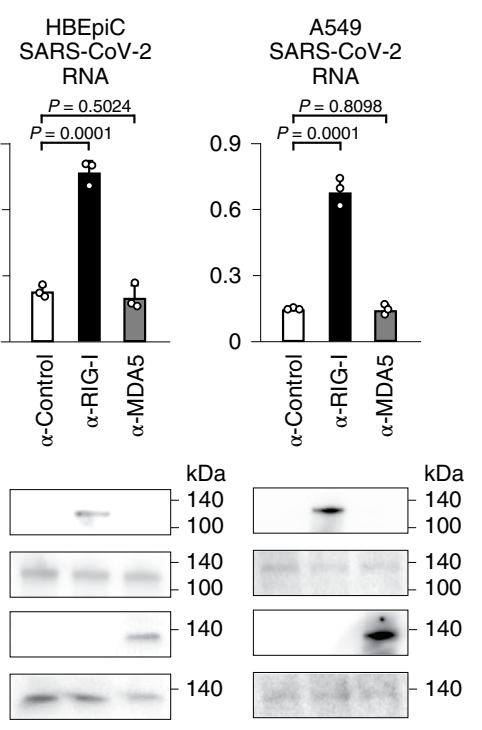

b
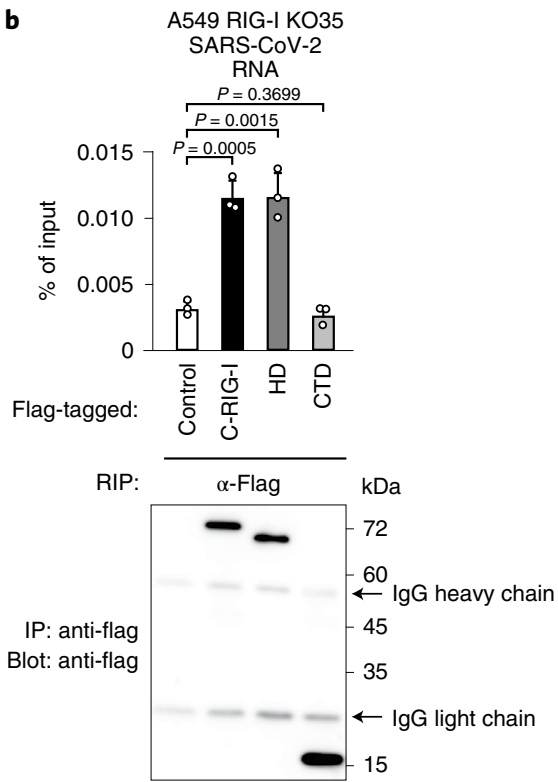

c

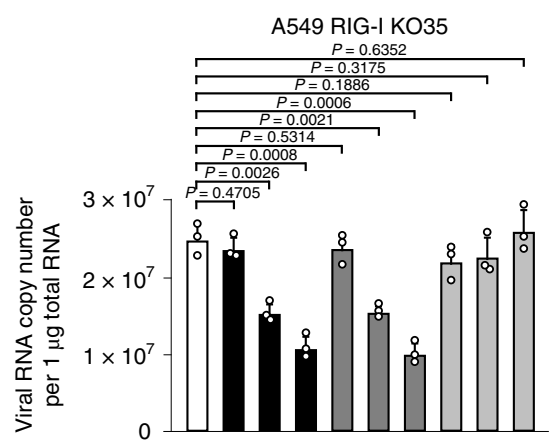

SARS-CoV-2 (24h): ++++++++++

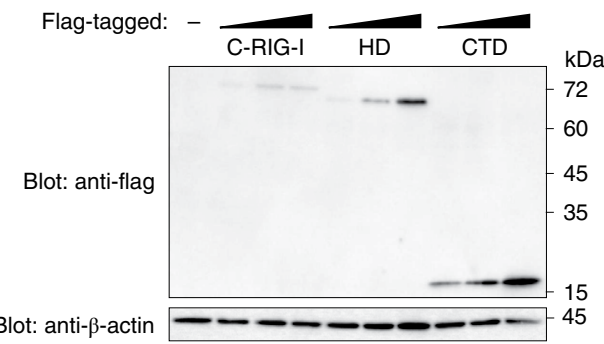

f

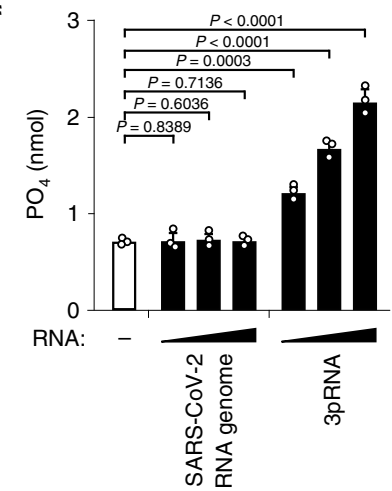

d

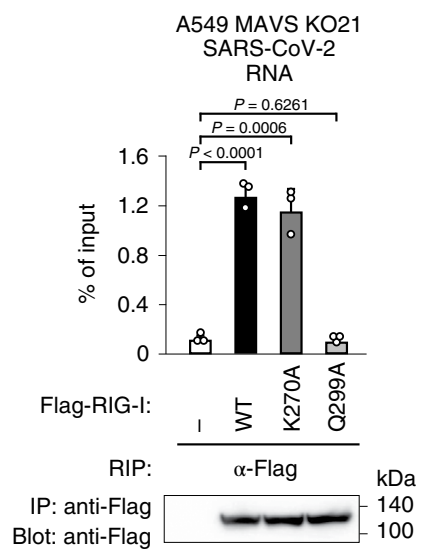

e

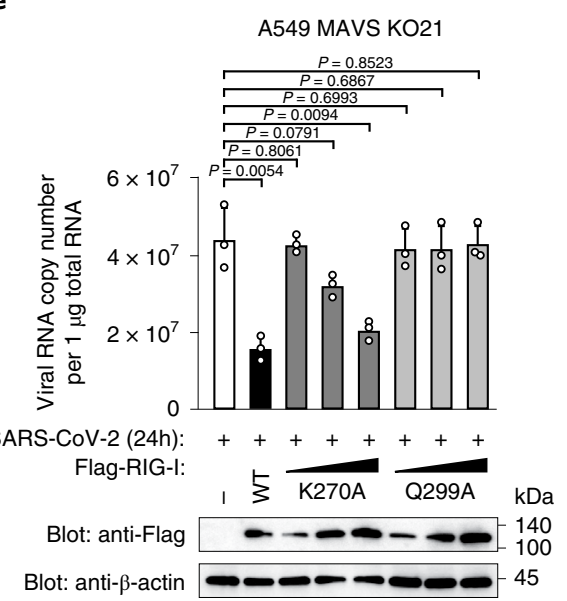

RIG-I HD but not the CTD selectively interacts with the $3^{\prime}$ UTR of the SARS-CoV-2 RNA genome, which resultantly failed to activate the ATPase activity and to interact with MAVS. These results suggest a unique viral recognition mode of RIG-I.
Furthermore, it would be intriguing to consider that this abortion of RIG-I signaling is a viral strategy to evade the innate immune system, which might be evolved by SARS-CoV-2. At this moment, we could not clearly rule out the possibility that some viral protein(s) 
a
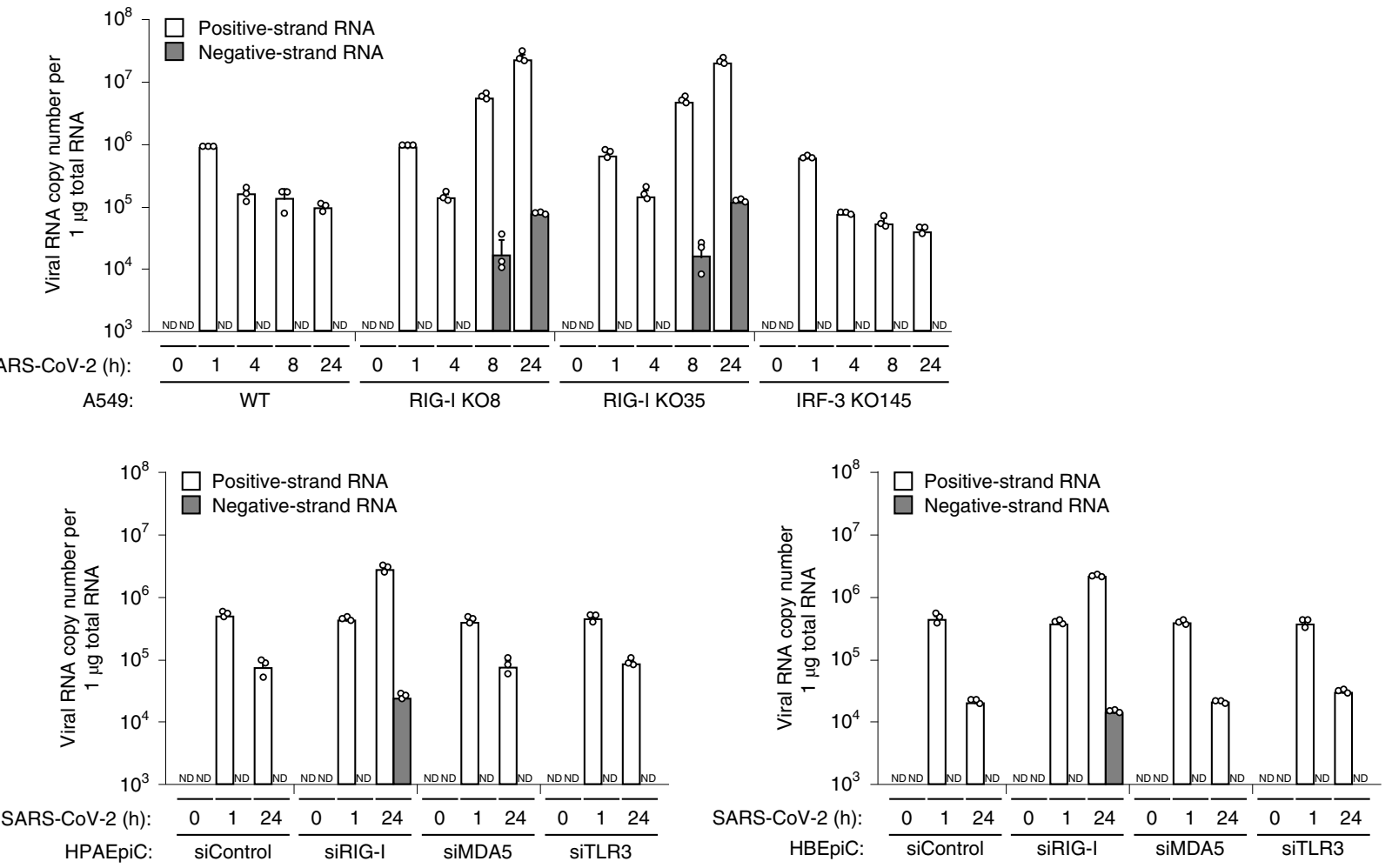

c

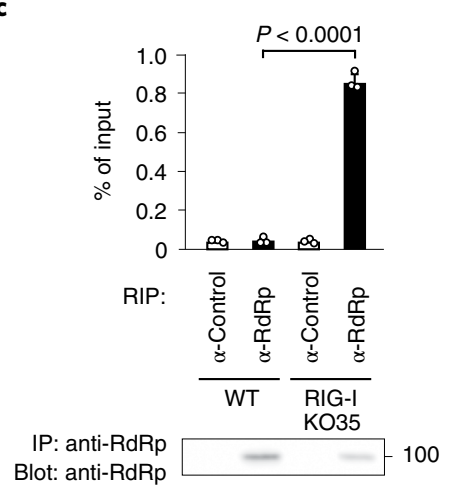

d

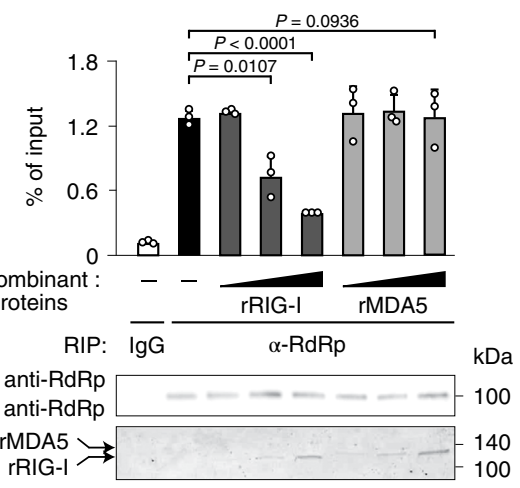

e

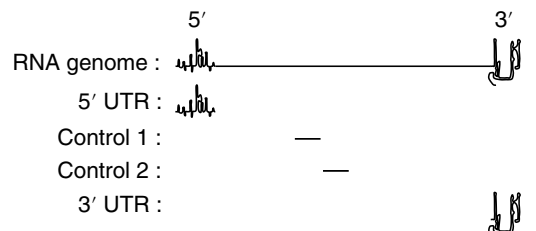

析

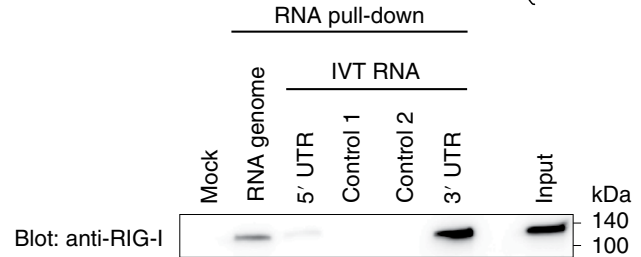

f
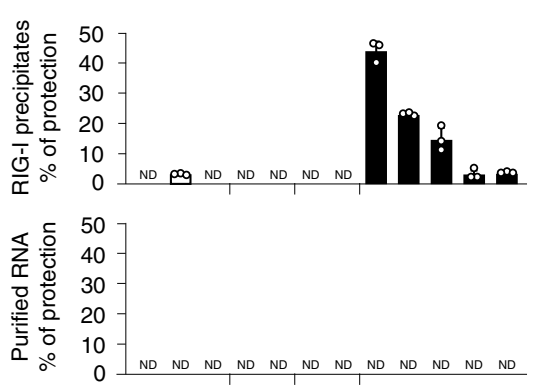

RNase $\mathrm{H}$ target sites:

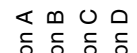

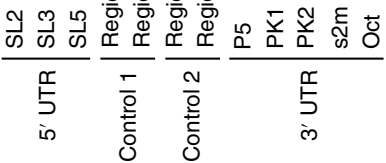

might block the activation of the conventional IRF-NF- $\mathrm{kB}$ pathway downstream of RIG-I, as previously reported ${ }^{9-11}$. However, our data showed that the RIG-I interaction with the SARS-CoV-2 RNA genome does not require the RIG-I CTD, which is critical to trigger the activation of the conventional RIG-I pathway. Actually, an IFN- $\beta$ response was not observed upon stimulation with the $3^{\prime}$ UTR 
Fig. 4 | RIG-I directly counteracts the access of RdRp to the viral RNA genome to shut off viral replication. a, Copy number of SARS-CoV-2 positive-strand or negative-strand RNA at $0,1,4,8$ or $24 \mathrm{~h}$ after infection with SARS-CoV-2 in A549 WT, RIG-I KO8, KO35 or IRF-3 KO145 cells ( $n=3$ biologically independent samples). b, Copy number of SARS-CoV-2 positive-strand or negative-strand RNA at 0, 1 or $24 \mathrm{~h}$ after infection with SARS-CoV-2 in HPAEpiC (left) or HBEpiC (right) cells transfected with indicated siRNAs ( $n=3$ biologically independent samples). c, RIP assay with A549 WT or RIG-I KO35 cell lysates prepared after $6 \mathrm{~h}$ of infection with SARS-CoV-2 by using anti-RdRp. The immunoprecipitated SARS-CoV-2 positive-strand RNA was quantified by RT-qPCR and is represented as fraction of input RNA before immunoprecipitation (percentage of input; upper; $n=3$ biologically independent samples). Immunoblot analysis of immunoprecipitated RdRp (lower). d, A549 RIG-I KO35 cell lysates prepared after $6 \mathrm{~h}$ of infection with SARS-CoV-2 were incubated with rRIG-I or rMDA5. The interaction of SARS-CoV-2 positive-strand RNA with RdRp was analyzed by RIP assay and RT-qPCR analysis as described in c (upper; $n=3$ biologically independent samples). Immunoblot analysis of immunoprecipitated RdRp and Coomassie Brilliant Blue (CBB) staining of recombinant proteins (lower). e, RNA pull-down assay showing the binding activity of SARS-CoV-2 RNA genome or IVT RNAs to rRIG-I. f, RNase $\mathrm{H}$ protection of SARS-CoV-2 positive-strand RNA in RIG-I immunoprecipitates from A549 cell lysates prepared after $6 \mathrm{~h}$ of infection with SARS-CoV-2. RNA products were quantified by RT-qPCR and were represented as a fraction of RNase H-untreated RNA (percentage of input; upper). Purified total RNAs were used as a positive control (lower; $n=3$ biologically independent samples). Oligonucleotide-targeted regions were designed in the 5' UTR (SL2, SL3 and SL5), the 3' UTR (P5, PK1, PK2, s2m and Oct; ${ }^{35}$ ) or regions A-D (11670-11681, 11758-11769, 12303-12314 or 12382-12393 nucleotide regions of the SARS-CoV-2 RNA genome). Data are presented as the mean values \pm s.d. and are representative of at least two independent experiments with similar results. Statistical significance was determined by two-tailed Student's $t$-test.

of SARS-CoV-2 RNA genome (Extended Data Fig. 8a) and the $3^{\prime}$ UTR still interacted with rRIG-I (Lys888Glu) mutant, which cannot bind to conventional RIG-I ligands such as 3pRNA and poly(rI:rC; Extended Data Fig. 8b). Therefore, we posit that the unique interaction between RIG-I HD and viral RNA occurs upon SARS-CoV-2 infection, which enables an unconventional, signaling-abortive mode of viral suppression. This strategic mechanism could partly explain why many individuals with SARS-CoV-2 infection tend to show asymptomatic or mild illness, which may be associated with the failure of efficient induction of long-lasting adaptive immunity ${ }^{35}$. Regarding possible viral evasion from the RIG-I-mediated antiviral defense mechanism that we have found in this study, the SARS-CoV-2-derived papain-like protease SCoV2-PLpro has recently been reported to decrease ISGylation of cellular proteins including IRF-3 (ref. ${ }^{36}$ ). Since RIG-I was reported to be ISGylated upon intracellular poly(I:C) stimulation ${ }^{37}$, we speculate that RIG-I may also be one of the target proteins by SCoV2-PLpro.

Taken together, our data have defined RIG-I expression levels as one of the intrinsic determinants for the defense in human lung cells at least during the initial process of SARS-CoV-2 infection. Actually, lung cells derived from patients with COPD, which showed reduced levels of RIG-I protein, were more susceptible to SARS-CoV-2 infection (Fig. $2 \mathrm{~g}$ ). Our data thus suggest the availability of RIG-I expression levels as one of the potential parameters for the prediction of patient outcomes. Our findings also suggest that upregulation of RIG-I expression by some agents such as ATRA (Fig. 2h) or IFNs ${ }^{38-40}$ may be available to enhance the preventive and/or therapeutic potential of COVID-19. Uncovering factors or conditions that modulate RIG-I expression levels are key for better understanding of SARS-CoV-2 pathogenicity and for the development of a new strategy to control SARS-CoV-2 infection.

\section{Online content}

Any methods, additional references, Nature Research reporting summaries, source data, extended data, supplementary information, acknowledgements, peer review information; details of author contributions and competing interests; and statements of data and code availability are available at https://doi.org/10.1038/ s41590-021-00942-0.

Received: 15 December 2020; Accepted: 26 April 2021; Published online: 11 May 2021

\section{References}

1. Takaoka, A. \& Yamada, T. Regulation of signaling mediated by nucleic acid sensors for innate interferon-mediated responses during viral infection. Int. Immunol. 31, 477-488 (2019).
2. Goubau, D., Deddouche, S. \& Reis e Sousa, C. Cytosolic sensing of viruses. Immunity 38, 855-869 (2013).

3. Gandhi, R. T., Lynch, J. B. \& del Rio, C. Mild or moderate COVID-19. N. Engl. J. Med. 383, 1757-1766 (2020).

4. Sanchez-Ramirez, D. C. \& Mackey, D. Underlying respiratory diseases, specifically COPD, and smoking are associated with severe COVID-19 outcomes: a systematic review and meta-analysis. Respir. Med. 171, $106096(2020)$

5. Zhao, Q. et al. The impact of COPD and smoking history on the severity of COVID-19: a systemic review and meta-analysis. J. Med. Virol. 92, 1915-1921 (2020).

6. Guan, W. J. et al. Clinical characteristics of coronavirus disease 2019 in China. N. Engl. J. Med. 382, 1708-1720 (2020).

7. Oran, D. P. \& Topol, E. J. Prevalence of asymptomatic SARS-CoV-2 infection: a narrative review. Ann. Intern. Med. 173, 362-367 (2020).

8. Kowalinski, E. et al. Structural basis for the activation of innate immune pattern-recognition receptor RIG-I by viral RNA. Cell 147, 423-435 (2011).

9. Thoms, M. et al. Structural basis for translational shutdown and immune evasion by the Nsp1 protein of SARS-CoV-2. Science 369, 1249-1255 (2020).

10. Lei, X. et al. Activation and evasion of type I interferon responses by SARS-CoV-2. Nat. Commun. 11, 3810 (2020).

11. Konno, Y. et al. SARS-CoV-2 ORF3b is a potent interferon antagonist whose activity is increased by a naturally occurring elongation variant. Cell Rep. 32, 108185 (2020).

12. de Wit, E., van Doremalen, N., Falzarano, D. \& Munster, V. J. SARS and MERS: recent insights into emerging coronaviruses. Nat. Rev. Microbiol. 14, 523-534 (2016).

13. Hoffmann, M. et al. SARS-CoV-2 cell entry depends on ACE2 and TMPRSS 2 and is blocked by a clinically proven protease inhibitor. Cell 181, 271-280 (2020).

14. Zipeto, D., Palmeira, J. D. F., Arganaraz, G. A. \& Arganaraz, E. R. ACE2/ ADAM17/TMPRSS2 interplay may be the main risk factor for COVID-19. Front. Immunol. 11, 576745 (2020).

15. Hadjadj, J. et al. Impaired type I interferon activity and inflammatory responses in severe COVID-19 patients. Science 369, 718-724 (2020).

16. Lucas, C. et al. Longitudinal analyses reveal immunological misfiring in severe COVID-19. Nature 584, 463-469 (2020).

17. Blanco-Melo, D. et al. Imbalanced host response to SARS-CoV-2 drives development of COVID-19. Cell 181, 1036-1045 (2020).

18. Long, Q. X. et al. Clinical and immunological assessment of asymptomatic SARS-CoV-2 infections. Nat. Med. 26, 1200-1204 (2020).

19. Le Bert, N. et al. SARS-CoV-2-specific T cell immunity in cases of COVID-19 and SARS, and uninfected controls. Nature 584, 457-462 (2020).

20. Rydyznski Moderbacher, C. et al. Antigen-specific adaptive immunity to SARS-CoV-2 in acute COVID-19 and associations with age and disease severity. Cell 183, 996-1012 (2020).

21. Attaway, A. A., Zein, J. \& Hatipoglu, U. S. SARS-CoV-2 infection in the COPD population is associated with increased healthcare utilization: an analysis of Cleveland clinic's COVID-19 registry. EClinicalMedicine 26, 100515 (2020).

22. Sin, D. D. COVID-19 in COPD: a growing concern. EClinicalMedicine 26, 100546 (2020).

23. García-Valero, J. et al. Deficient pulmonary IFN- $\beta$ expression in COPD patients. PLoS ONE 14, e0217803 (2019).

24. Liu, T. X. et al. Gene expression networks underlying retinoic acidinduced differentiation of acute promyelocytic leukemia cells. Blood 96, 1496-1504 (2000). 
25. Zhong, X. et al. ZFYVE1 negatively regulates MDA5- but not RIG-I-mediated innate antiviral response. PLoS Pathog. 16, e1008457 (2020).

26. Takahasi, K. et al. Nonself RNA-sensing mechanism of RIG-I helicase and activation of antiviral immune responses. Mol. Cell. 29, 428-440 (2008).

27. Plumet, S. et al. Cytosolic 5'-triphosphate ended viral leader transcript of measles virus as activator of the RIG I-mediated interferon response. PLoS ONE 2, e279 (2007).

28. Rangan, R. et al. RNA genome conservation and secondary structure in SARS-CoV-2 and SARS-related viruses: a first look. RNA 26, 937-959 (2020).

29. Sola, I., Almazán, F., Zúñiga, S. \& Enjuanes, L. Continuous and discontinuous RNA synthesis in coronaviruses. Annu. Rev. Virol. 2, 265-288 (2015).

30. Züst, R., Miller, T. B., Goebel, S. J., Thiel, V. \& Masters, P. S. Genetic interactions between an essential $3^{\prime}$ cis-acting RNA pseudoknot, replicase gene products, and the extreme $3^{\prime}$ end of the mouse coronavirus genome. J. Virol. 82, 1214-1228 (2008).

31. Yin, X. et al. MDA5 governs the innate immune response to SARS-CoV-2 in lung epithelial cells. Cell Rep. 34, 108628 (2021).

32. Sato, S. et al. The RNA sensor RIG-I dually functions as an innate sensor and direct antiviral factor for hepatitis B virus. Immunity 42, 123-132 (2015).

33. Weber, M. et al. Influenza virus adaptation PB2-627K modulates nucleocapsid inhibition by the pathogen sensor RIG-I. Cell Host Microbe 17, 309-319 (2015).
34. Yao, H. et al. ATP-dependent effector-like functions of RIG-I-like receptors. Mol. Cell. 58, 541-548 (2015).

35. Ibarrondo, F. J. et al. Rapid decay of anti-SARS-CoV-2 antibodies in persons with mild COVID-19. N. Engl. J. Med. 383, 1085-1087 (2020).

36. Shin, D. et al. Papain-like protease regulates SARS-CoV-2 viral spread and innate immunity. Nature 587, 657-662 (2020)

37. Kim, M.-J., Hwang, S.-Y., Imaizumi, T. \& Yoo, J.-Y. Negative feedback regulation of RIG-I-mediated antiviral signaling by interferon-induced ISG15 conjugation. J. Virol. 82, 1474-1483 (2008).

38. Wang, N. et al. Retrospective multicenter cohort study shows early interferon therapy is associated with favorable clinical responses in COVID-19 patients. Cell Host Microbe 28, 455-464 (2020).

39. Zhou, Q. et al. Interferon- $\alpha 2 b$ treatment for COVID-19. Front. Immunol. 11 , 1061 (2020).

40. Felgenhauer, U. et al. Inhibition of SARS-CoV-2 by type I and type III interferons. J. Biol. Chem. 295, 13958-13964 (2020).

Publisher's note Springer Nature remains neutral with regard to jurisdictional claims in published maps and institutional affiliations.

(C) The Author(s), under exclusive licence to Springer Nature America, Inc. 2021 


\section{Methods}

Viruses, cells, antibodies and reagents. SARS-CoV-2 (JPN/TY/WK-521) was obtained from the National Institute of Infectious Diseases (Tokyo, Japan) ${ }^{41}$. Influenza virus (strain A/Puerto Rico/8/34) was from T. Miyazaki (Hokkaido University, Japan). EMCV was previously used ${ }^{42}$. A549 cells (CCL-185), Vero E6 cells (CRL-1586), Calu-3 cells (HTB-55), HEK293T cells (CRL-3216), Vero cells (CCL-81) and Madin-Darby canine kidney (MDCK) cells (CCL-34) were obtained from American Type Culture Collection (ATCC) and maintained in DMEM (Nissui) supplemented with $10 \%$ FBS. These cells were incubated at $37^{\circ} \mathrm{C}$ with $5 \% \mathrm{CO}_{2}$. Sf9 cells (B82501) were purchased from Invitrogen and routinely grown at $28^{\circ} \mathrm{C}$ in a Sf-900 II SFM medium (Gibco) supplemented with 5\% heat-inactivated FBS. Human Pulmonary Alveolar Epithelial Cells (HPAEpiC; 3200), human bronchial epithelial cells (HBEpiC; 3210) and human colonic epithelial cells (HCoEpiC; 2950) were purchased from ScienCell and cultured in alveolar epithelial cell medium (ScienCell), bronchial epithelial cell medium (ScienCell) and colonic epithelial cell medium (ScienCell), respectively. Human bronchial epithelial cells (HBEpC; CA50205a) and HBEpC-COPD (CA502COPDK05a) cells were obtained from Cell Applications and maintained in bronchial/tracheal epithelial cell basal medium with growth supplement (Cell Applications) except for retinoic acid. Primary bronchial/tracheal epithelial cells-COPD (PBEC-COPD; PCS-300-013) were from ATCC and grown in airway epithelial cell basal medium using a Bronchial Epithelial Cell Growth Kit (ATCC). All cells were incubated at $37^{\circ} \mathrm{C}$ with $5 \% \mathrm{CO}_{2}$. Antibodies were used as follows: anti-IRF-3 (p.Ser 396; 4D4G; Cell Signaling), anti-IRF-3 (D6I4C; Cell Signaling), anti-IкB $\alpha$ (p.Ser 32; 14D4; Cell Signaling), anti-IкB $\alpha$ (44D4; Cell Signaling), anti-RIG-I (D14G6; Cell Signaling, 1C3; Kerafast), anti-MAVS (ab25084; Abcam), anti-ACE2 (N1N2; GeneTex), anti-TMPRSS2 (N2C3; GeneTex), anti- $\beta$-actin (AC-15; Sigma), anti-spike (1A9; GeneTex), anti-Flag (M2; Sigma), anti-MDA5 (D74E4; Cell Signaling), anti-RdRp (4E6; Novus Biologicals) and goat anti-mouse IgG secondary antibody conjugated to Alexa Fluor 488 (A11029; Molecular Probes). Working dilutions of antibodies for immunoblotting were as follows: anti-IRF-3 (p.Ser 396; 4D4G), 1:1,000; anti-IRF-3 (D6I4C), 1:1,000; anti-IкB $\alpha$ (p.Ser 32; 14D4), 1:1,000; anti-IкB $\alpha$ (44D4), 1:1,000; anti-RIG-I (D14G6), 1:1,000; anti-MAVS (ab25084), $1 \mu \mathrm{g} \mathrm{ml}^{-1}$, anti-ACE2 (N1N2), 1:500; anti-TMPRSS2 (N2C3), 1:500; anti- $\beta$-actin (AC-15), 1:1,000; anti-Flag (M2), 1:1,000; anti-MDA5 (D74E4), 1:1,000; and anti-RdRp (4E6), 1:500. Working dilutions of antibodies for immunoprecipitation were as follows: anti-MAVS (ab25084), $1 \mu \mathrm{g} \mathrm{mg}^{-1}$ total protein; anti-RIG-I (1C3), 1:50; anti-MDA5 (D74E4), 1:100; anti-Flag (M2), $1 \mu \mathrm{g} \mathrm{mg}^{-1}$ total protein; and anti-RdRp (4E6), 1:50. Working dilutions of antibodies for fluorescence analysis were as follows: anti-spike (1A9; GeneTex), 1:100; goat anti-mouse IgG secondary antibody conjugated to Alexa Fluor $488 ; 2 \mu \mathrm{g} \mathrm{ml}^{-1}$. Lipofectamine RNAiMAX (Invitrogen) was used for transfection of siRNA into the cytoplasm. FuGENE HD (Promega) reagent, Lipofectamine RNAiMAX and Lipofectamine 2000 (Invitrogen) were used for gene transfer with lipid transfection. ATRA was purchased from Sigma.

Preparation of viral stocks. SARS-CoV-2 (JPN/TY/WK-521) was obtained from the National Institute of Infectious Diseases (Tokyo, Japan). To generate viral stocks of SARS-CoV-2, Vero E6-TMPRSS2 cells were inoculated with SARS-CoV-2 (JPN/TY/WK-521) with Mynox mycoplasma elimination reagent (Minerva Biolabs) ${ }^{41}$. Influenza virus (strain A/Puerto Rico/8/34) was from T. Miyazaki (Hokkaido University, Japan). MDCK cells or IFNAR1-deficient mouse embryonic fibroblasts were infected with influenza virus (strain A/Puerto Rico/8/34) or EMCV for propagation, respectively, as previously reported ${ }^{42}$. These supernatants of infected cells were collected and clarified by centrifugation. Viral titers were determined by plaque assay. These viral stocks were maintained at $-80^{\circ} \mathrm{C}$. The experiments with infectious SARS-CoV-2 or influenza virus were performed in a Biosafety Level 3 or 2 laboratory, respectively, and approved by the Hokkaido University Biosafety Committee.

Generation of TMPRSS2-expressing Vero E6 cells. The cDNA of human TMPRSS2 was cloned into the self-inactivating lentiviral vector plasmids, CSII-CMV-MCS-IRES2-Bsd (RIKEN BRC). For lentiviral vector preparation, HEK293T cells were co-transfected with the lentiviral vector plasmid and Lentiviral High Titer Packaging Mix (TAKARA). Vero E6 cells were treated with the culture supernatant containing lentiviral vector, and then the cells stably expressing TMPRSS2 (Vero E6-TMPRSS2) were selected with blasticidin S.

Viral infection and measurement of viral titers. A549, Calu-3, HPAEpiC, HBEpiC, HBEpC, HCoEpiC, HBEpC-COPD or PBEC-COPD cells were infected with SARS-CoV-2 (multiplicity of infection (m.o.i.) of 1 ) FluV (1 m.o.i.) or EMCV (1 m.o.i.). Cells were infected for $1 \mathrm{~h}$ at $37^{\circ} \mathrm{C}$ with SARS-CoV-2 in DMEM with $10 \%$ FBS, with FluV in serum-free MEM containing BSA and trypsin, or with EMCV in FBS-free DMEM. The supernatants of cells infected with SARS-CoV-2 were collected $5 \mathrm{~d}$ after infection. Vero E6-TMPRSS2 cells were used for the plaque-forming assay to determine the titers of SARS-CoV-2. Monolayers of Vero E6-TMPRSS2 cells were inoculated with serial dilutions of the cell supernatants for $1 \mathrm{~h}$ at $37^{\circ} \mathrm{C}$, and then, overlaid with DMEM containing $0.5 \%$ Bacto Agar (Becton
Dickinson). At $3 \mathrm{~d}$ after infection, plaques were measured. A plaque-forming assay with MDCK cells or Vero cells was conducted to measure the titers of FluV or EMCV, respectively.

Immunoblotting. Cell lysis and immunoblot analysis were performed as described previously ${ }^{12,43}$. An Amersham Imager 680 was used for chemiluminescence detection.

RT-qPCR analysis. Total RNAs were isolated from cultured cells by using ISOGEN (Nippon Gene), and were treated with DNase I (Invitrogen). cDNAs were prepared from total RNAs by using ReverTra Ace (TOYOBO). For strand-specific detection of viral RNA, reverse transcription was performed with each forward and reverse PCR primer for negative-strand and positive-strand specific reverse transcription, respectively. Quantitative PCR was performed using SYBR Premix Ex Taq (TAKARA) and analyzed on a StepOnePlus real-time PCR system (Applied Biosystems). Detailed information about the primers used is available in Supplementary Table 1. Data were normalized to the expression levels of ACTB for each sample.

siRNA-mediated gene silencing. Chemically synthesized 21-nucleotide siRNAs, including control siRNA (MISSION siRNA Universal Negative Control), were obtained from Sigma (for sequence information, see Supplementary Table 2). In total, $1 \times 10^{5}$ cells of A549, Calu-3, HPAEpiC or HBEpiC were transfected with $50 \mathrm{nM}$ siRNA in $2.0 \mu \mathrm{l}$ Lipofectamine RNAiMAX. At $48 \mathrm{~h}$ after transfection, the cells were used for further experiments.

Generation of gene knockout A549 cells. Target sequences G/A-(N19)-NGG were selected with the online CRISPRdirect program ${ }^{44}$ (https://crispr.dbcls.jp) or from those previously used ${ }^{45}$. These sequences are shown in Extended Data Figs. 2-5 and inserted into pX330-U6-Chimeric_BB-CBh-hSpCas9 vector (Addgene) according to the manual. A549 cells were transfected with the pX330 vector with Lipofectamine 2000 (Invitrogen) or FuGENE HD (Promega) and, $72 \mathrm{~h}$ later, single-cell clones were isolated. The knockout phenotype of these clones was confirmed by genome sequencing (Applied Biosystems) and western blotting (Extended Data Figs. 2-5).

Plasmids and molecular cloning. The cDNAs for human RIG-I, MDA5 and the related mutants ${ }^{32}$ (C-RIG-I; amino acids 173-925: HD; amino acids 194-791: CTD; amino acids 792-925) of RIG-I were obtained by RT-PCR of total RNAs from HEK293T cells. For Flag-tagged proteins, cDNA was cloned into the XhoI and NotI sites of the pCXN2-Flag vector. The nucleotide sequence of each cDNA was confirmed with the BigDye Terminator v3.1 sequencing kit (Applied Biosystems). For the generation of expression plasmids for recombinant proteins, the cDNAs for glutathione S-transferase (GST)-tagged RIG-I or MDA5 were cloned into BamHI and HindIII sites of the pFastBacl vector (Invitrogen).

Fluorescence analysis. A549 cells were infected with SARS-CoV-2 (0.1 m.o.i.) for 0 or $72 \mathrm{~h}$. SARS-CoV-2 spike protein was visualized with anti-spike antibody and the appropriate secondary antibody conjugated to Alexa Fluor 488 (Molecular Probes). Hoechst 33342 (Invitrogen) was used for the counterstaining of nuclei. The localization was examined with an IX-81S confocal microscope (Olympus).

RNA-immunoprecipitation assay. The RIP assay was conducted using the RIP assay kit according to the manufacturer's protocol with minor modification (MBL). A549 WT or RIG-I KO35 cells, and HPAEpiC, HBEpiC or Calu-3 cells infected with SARS-CoV-2 for $6 \mathrm{~h}$ or $24 \mathrm{~h}$ were lysed with $500 \mu \mathrm{l}$ of lysis buffer and precleared with Protein-G Sepharose beads. A total of $20 \mu$ of the supernatant was saved as input. Anti-RIG-I, anti-MDA5, anti-Flag, anti-RdRp or control IgG was added to cell lysates with or without recombinant RIG-I or MDA5 protein $(0.75$, 1.5 or $3 \mathrm{nM}$ ) and gently rotated overnight at $4^{\circ} \mathrm{C}$. Then, Protein-G Sepharose beads were added and further incubated with gentle shaking. One hour later, beads were washed three times with wash buffer and divided into two. One was eluted with Laemmli buffer and analyzed by immunoblotting for checking the precipitated protein, and the other was used for the elution of the precipitated RNAs and analyzed by RT-qPCR with specific primers to detect SARS-CoV-2 RNA. The amount of immunoprecipitated RNAs is represented as the percentile of the amount of input RNA (percentage input).

Viral cross-linking and solid-phase purification (VIR-CLASP). To analyze the specific interaction of endogenous RIG-I and SARS-CoV-2 RNA genome, we used VIR-CLASP that was designed to minimize nonspecific interactions for the characterization of the interactions between incoming viral RNA and cellular proteins $^{46,47}$. This assay was referred to in the protocol of a previous paper ${ }^{46,47}$. To generate viral stocks of unlabeled or 4-thiouridine (4SU)-labeled SARS-CoV-2, Vero E6-TMPRSS2 cells were inoculated with SARS-CoV-2 with or without 4SU $(100 \mu \mathrm{M})$. These supernatants of infected cells were collected and clarified by centrifugation. Viral titers were determined by plaque assay. These viral stocks were maintained at $-80^{\circ} \mathrm{C}$. Unlabeled $3 \times 10^{6} \mathrm{~A} 549$ cells were infected with SARS-CoV-2 or 4SU-SARS-CoV-2 (1 m.o.i.) for $1 \mathrm{~h}$ and then washed with PBS and 
maintained in DMEM. At $6 \mathrm{~h}$ later, cells were washed with PBS and irradiated with $365 \mathrm{~nm}$ of ultraviolet light. Cells were lysed with $900 \mu \mathrm{l}$ of $1 \times$ denaturation buffer (50 mM Tris- $\mathrm{HCl}$ (pH 6.8), 10\% glycerol, 2.5\% SDS and 0.67\% NP-40). Then, $20 \mu \mathrm{l}$ of the supernatant was saved for checking protein input. The CLASP step was performed according to the protocol of a previous paper $^{32}$. The precipitated proteins were used for immunoblot with anti-RIG-I or anti-MDA5 antibodies.

\section{Purification of recombinant proteins. GST-tagged RIG-I and MDA5 were} expressed in Sf9 cells according to the manufacturer's instructions for Bac-to-Bac baculovirus expression system (Gibco) and purified with Glutathione Sepharose 4B (GE Healthcare). GST protein of recombinant protein was cleaved with Precision protease (GE Healthcare)

In vitro ATPase assay. ATPase activity of the recombinant RIG-I protein was measured by phosphate-release assay with BIOMOL Green reagent (Enzo Life Sciences). The purified RIG-I protein $(0.1 \mu \mathrm{g})$ in $20 \mu \mathrm{l}$ of ATPase reaction buffer (20 mM Tris- $\mathrm{HCl}(\mathrm{pH} 8.0), 1.5 \mathrm{mM} \mathrm{MgCl}_{2}$ and $1.5 \mathrm{mM}$ dithiothreitol (DTT)) were incubated for $15 \mathrm{~min}$ at $37^{\circ} \mathrm{C}$ with $0,0.001,0.1$ or $10 \mu \mathrm{g}$ of SARS-CoV-2 RNA genome or $3 \mathrm{pRNA}$, then further incubated for $15 \mathrm{~min}$ at $37^{\circ} \mathrm{C}$ with $5 \mathrm{nmol}$ ATP. These samples or a series of phosphate standard (Enzo Life Sciences) were added to a 96-well plate, followed by addition of $180 \mu \mathrm{l}$ of BIOMOL Green reagent. The malachite green was quantified by reading the absorbance at $620 \mathrm{~nm}$, and then the phosphate was measured.

Preparation of nucleic acids. Purification of nucleic acids for RNA pull-down assay was conducted as previously described with minor modification ${ }^{32}$. Full RNA genome of SARS-CoV-2 was purified from supernatant of Vero E6-TMPRSS2 cells infected with SARS-CoV-2 by TRIzol (Thermo Fisher). To generate the $5^{\prime}$ UTR, 3' UTR, control 1 and control 2, cDNA of the RNA genome of SARS-CoV-2 was used for PCR to prepare templates of the subsequent in vitro transcription. Detailed information about the primers used here is available in Supplementary Table 3. To avoid the non-templated nucleotide addition to the $3^{\prime}$ terminus of transcribed RNAs, primers for the generation of antisense strands were modified with $2^{\prime}$-O-methylation $\left(2^{\prime}\right.$-OMe $)$ at the first two nucleotides of the $5^{\prime}$ terminus ${ }^{48}$. About $100 \mathrm{ng}$ of these PCR products was used as a template for in vitro transcription under the control of the T7 promoter with MEGAscript (Invitrogen) in the presence of Ribo $\mathrm{m} 7 \mathrm{G}$ cap analog ( $7.5 \mathrm{mM}$; Promega). The integrity of in vitro generated RNAs was checked by formaldehyde gel electrophoresis. These RNAs were additionally dephosphorylated with Alkaline phosphatase (Roche) to completely remove triphosphate-modified RNAs. These regions of 5' UTR and 3' UTR were designed in accordance with a previous report ${ }^{28}$. Control 1 and control 2 were designed not to make secondary structure by M-folds software (http://mfold. rna.albany.edu). 3 pRNA was prepared as reported previously ${ }^{32,42,43}$. Poly(rI:rC) was purchased from GE healthcare.

RNA pull-down assay. The full RNA genome of SARS-CoV-2, in vitro-transcribed RNAs described above, 3pRNA and poly(rI:rC) were labeled with biotin using the Label IT Biotin Labeling Kit (Mirus). Biotin-labeled RNA (30 nM) was incubated with recombinant RIG-I protein $(3 \mathrm{nM})$ in $500 \mu \mathrm{l}$ of buffer $(20 \mathrm{mM}$ Tris- $\mathrm{HCl}$, $150 \mathrm{mM} \mathrm{NaCl}, 1 \mathrm{mM}$ EDTA, $1 \%$ NP-40, $1 \mathrm{mM}$ phenylmethyl sulfonyl fluoride and $1 \mathrm{mM} \mathrm{DTT}$ and $1 \mu \mathrm{g} \mathrm{ml}^{-1}$ leupeptin ( $\left.\mathrm{pH} 7.4\right)$ ) for $1 \mathrm{~h}$ with gentle shaking at $4{ }^{\circ} \mathrm{C}$. Subsequently, Dynabeads M-280 Streptavidin (Invitrogen) were added and incubated for $1 \mathrm{~h}$ with gentle shaking. Beads were washed three times with wash buffer (20 mM Tris-HCl, $150 \mathrm{mM} \mathrm{NaCl}, 1 \mathrm{mM}$ EDTA and 1\% NP-40 (pH 7.4)). The pull-down complexes were eluted with Laemmli buffer and analyzed by immunoblotting with the antibody for RIG-I.

RIP assay with RNA competition. Around $3 \times 10^{6}$ HPAEpiC, HBEpiC or A549 cells infected with SARS-CoV-2 for $6 \mathrm{~h}$ were lysed with $500 \mu \mathrm{l}$ of lysis buffer of the RIP assay kit according to the manufacturer's protocol (MBL). The lysates were incubated with or without in vitro-transcribed RNAs $(10 \mu \mathrm{g})$ described above for $2 \mathrm{~h}$ at $4{ }^{\circ} \mathrm{C}$ with gentle shaking. The remaining steps were performed per the RIP assay.

ELISA. Human IFN- $\beta$ protein in cell culture supernatants at $24 \mathrm{~h}$ after transfection of $3^{\prime}$ UTR, 3pRNA or poly(rI:rC) were measured by ELISA according to the manufacturer's protocol (PBL).

Treatment with all-trans retinoic acid. ATRA was dissolved in DMSO to $10 \mathrm{mM}$. Next, $1 \times 10^{5}$ HBEpC-COPD or PBEC-COPD cells were seeded on 12-well plates and treated with ATRA $(0.01,0.1$ or $1 \mu \mathrm{M})$ for $24 \mathrm{~h}$, and then subjected to further experiment.

Oligonucleotide-targeted RNase $\mathbf{H}$ protection assay. This assay was conducted in part by referring to the protocol of the previous study ${ }^{49}$. Approximately $1 \times 10^{6}$ A549 cells were infected with SARS-CoV-2. At $6 \mathrm{~h}$ after infection, cells were lysed with $500 \mu \mathrm{l}$ of lysis buffer and precleared with Protein-G Sepharose beads according to the manufacturer's protocol of the RIP assay kit (MBL). Then, $20 \mu \mathrm{l}$ of the supernatant was saved for purification of total RNA. Anti-RIG-I or control
IgG was added to cell lysates and gently rotated overnight at $4{ }^{\circ} \mathrm{C}$. Then, Protein-G Sepharose beads were added and further incubated with gentle shaking. One hour later, beads were washed three times with wash buffer and divided into two. One was eluted with Laemmli buffer and analyzed by immunoblotting for checking the precipitated RIG-I protein, and the other was incubated in $25 \mu \mathrm{l}$ of reaction buffer (12 mM HEPES (pH 8.0), $60 \mathrm{mM} \mathrm{KCl,} 3 \mathrm{mM} \mathrm{MgCl}_{2}, 1 \mathrm{mM}$ DTT, $20 \mathrm{U}$ RNasin and $40 \mu \mathrm{g} \mathrm{ml}^{-1} \mathrm{DNA}$ oligonucleotide) with or without RNase $\mathrm{H}$ (Promega) at $30^{\circ} \mathrm{C}$ for $60 \mathrm{~min}$. For analysis of RNA cleavage efficiency, the reaction was terminated by adding $75 \mu \mathrm{l}$ of distilled $\mathrm{H}_{2} \mathrm{O}, 100 \mu \mathrm{l}$ of $2 \times$ proteinase $\mathrm{K}$ buffer $(200 \mathrm{mM}$ Tris- $\mathrm{HCl}$ (pH 7.5), $300 \mathrm{mM} \mathrm{NaCl}, 25 \mathrm{mM}$ EDTA and $2 \%$ SDS) and $4 \mu \mathrm{l}$ of proteinase $\mathrm{K}$ $\left(10 \mathrm{mg} \mathrm{ml}^{-1}\right)$ and then purified RNA, according to the manufacturer's protocol of the RIP assay kit (MBL). Purified total RNAs were used as positive controls for evaluation of efficiencies of RNase $\mathrm{H}$ cleavage based on each DNA oligonucleotide. Positive-strand SARS-CoV-2 RNA products were quantified by RT-qPCR with specific primers to detect each region of SARS-CoV-2 RNA. The amount of RNase H-treated RNAs is represented as the percentile of the amount of RNase $\mathrm{H}$-untreated RNA (percentage input). The DNA oligonucleotides used are listed in Supplementary Table 4. Oligonucleotide-targeted regions of 5' UTR (SL2, SL3 and SL5) and $3^{\prime}$ UTR (P5, PK1, PK2, s2m and Oct) were selected as referred to in a previous report ${ }^{28-30}$. Regions A-D were designed in 11670-11681, 11758-11769, 12303-12314 or 12382-12393 nucleotide regions of the SARS-CoV-2 RNA genome, respectively.

Statistical analysis. All statistical analyses were performed by Microsoft Excel (v16.3). For all experiments, at least two independent experiments were performed. Data are presented as the mean values \pm s.d. of biological triplicates. Experiments were evaluated by statistical significance with a two-tailed Student's $t$-test. Differences were considered significant at $P<0.05$.

Reporting Summary. Further information on research design is available in the Nature Research Reporting Summary linked to this article.

\section{Data availability}

Data that support the findings of this study are available from the corresponding author upon reasonable request. Source data are provided with this paper.

\section{References}

41. Matsuyama, S. et al. Enhanced isolation of SARS-CoV-2 by TMPRSS2-expressing cells. Proc. Natl Acad. Sci. USA 117, 7001-7003 (2020)

42. Yamada, T. et al. Constitutive aryl hydrocarbon receptor signaling constrains type I interferon-mediated antiviral innate defense. Nat. Immunol. 17, 687-694 (2016)

43. Hayakawa, S. et al. ZAPS is a potent stimulator of signaling mediated by the RNA helicase RIG-I during antiviral responses. Nat. Immunol. 12, 37-44 (2011).

44. Naito, Y., Hino, K., Bono, H. \& Ui-Tei, K. CRISPRdirect: software for designing CRISPR-Cas guide RNA with reduced off-target sites. Bioinformatics 31, 1120-1123 (2015).

45. Gao, L. et al. Tumor-derived exosomes antagonize innate antiviral immunity. Nat. Immunol. 19, 233-245 (2018).

46. Kim, B. et al. Discovery of widespread host protein interactions with the pre-replicated genome of CHIKV using VIR-CLASP. Mol. Cell. 78, 624-640 (2020)

47. Kim, B., Arcos, S., Rothamel, K. \& Ascano, M. Viral cross-linking and solid-phase purification enables discovery of ribonucleoprotein complexes on incoming RNA virus genomes. Nat. Protoc. 16, 516-531 (2021).

48. Kao, C., Zheng, M. \& Rüdisse, S. A simple and efficient method to reduce nontemplated nucleotide addition at the $3^{\prime}$ terminus of RNAs transcribed by T7 RNA polymerase. RNA 5, 1268-1272 (1999).

49. Günzl, A., Palfi, Z. \& Bindereif, A. Analysis of RNA-protein complexes by oligonucleotide-targeted RNase H digestion. Methods 26, 162-169 (2002).

\section{Acknowledgements}

We thank M. Shimojima (the National Institute of Infectious Diseases, Japan) for SARS-CoV-2 (JPN/TY/WK-521), H. Miyoshi (RIKEN RBC, Japan) for lentiviral vector CSII-CMV-MCS-IRES2-Bsd, T. Miyazaki for influenza virus (strain A/Puerto Rico/8/34) and J. Miyazaki for the pCXN2-Flag vector. This work was supported by grants from the Japan Society for the Promotion of Science (JSPS; Grant-in-Aid for Challenging Research (Pioneering), JP17H06265, to A.T.); Grant-in-Aid for Young Scientists (B; JP19K16664, to T.Y.); Japan Agency for Medical Research and Development (AMED; Program on the Innovative Development and the Application of New Drugs for Hepatitis B, JP18fk0310101 (to A.T.) and JP20fk0108251 (to H.S.)); the Naito Foundation and Asai Germanium Research Institute (to A.T.); Akiyama Life Science Foundation (to A.T.); and the Uehara Memorial Foundation (to A.T.) 


\section{Author contributions}

T.Y. carried out most of experiments and analyzed data. S.S. prepared recombinant proteins and knockout cells. Y.S. and H.Y. prepared knockout cells and analyzed data Y.O., H.S. and M.S. offered critical advice on the whole manuscript and contributed to establishment of the protocols for SARS-CoV-2 experiments. M.S. also prepared SARS-CoV-2 stock with titration. T.Y. and A.T. designed the project and wrote the manuscript with critical input from co-authors, which A.T. supervised. All authors contributed to discussing the results.

\section{Competing interests}

The authors declare no competing interests.

\section{Additional information}

Extended data is available for this paper at https://doi.org/10.1038/s41590-021-00942-0.

Supplementary information The online version contains supplementary material available at https://doi.org/10.1038/s41590-021-00942-0.

Correspondence and requests for materials should be addressed to A.T.

Peer review information Nature Immunology thanks Andrew Bowie and the other, anonymous, reviewer(s) for their contribution to the peer review of this work. Peer reviewer reports are available. Zoltan Fehervari was the primary editor on this article and managed its editorial process and peer review in collaboration with the rest of the editorial team.

Reprints and permissions information is available at www.nature.com/reprints. 
a

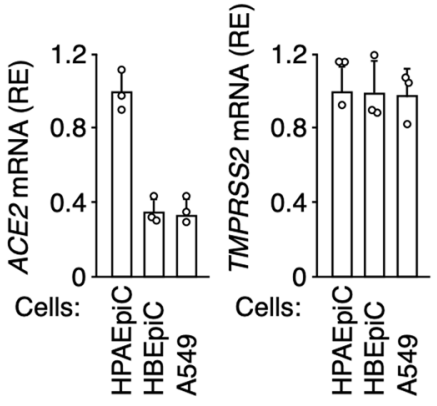

C
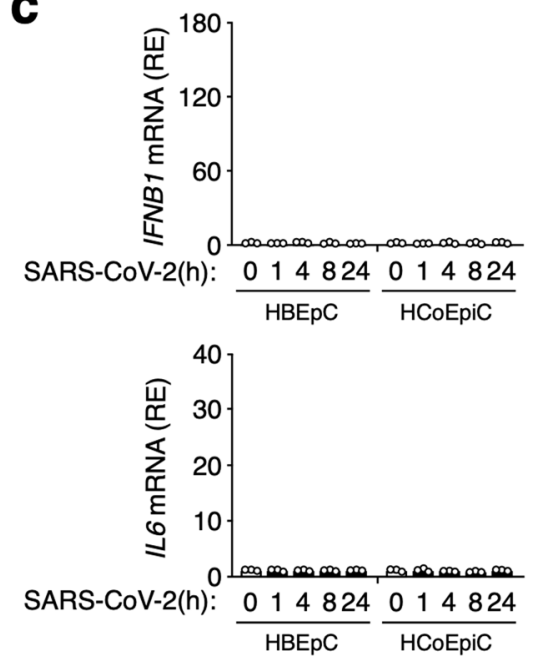

d

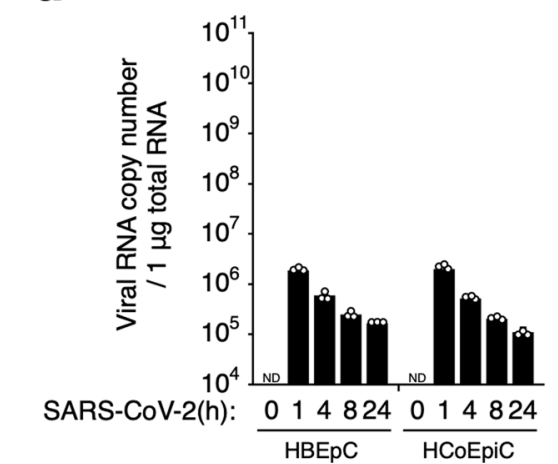

b

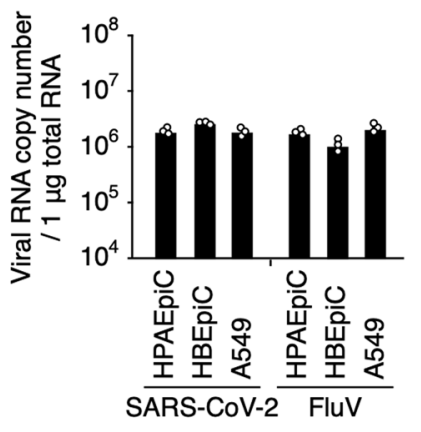

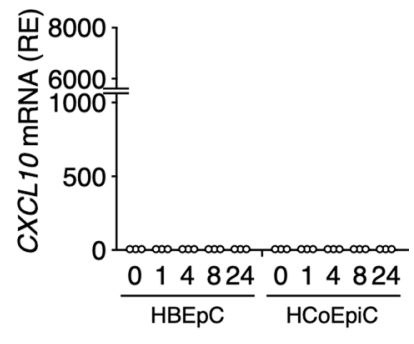

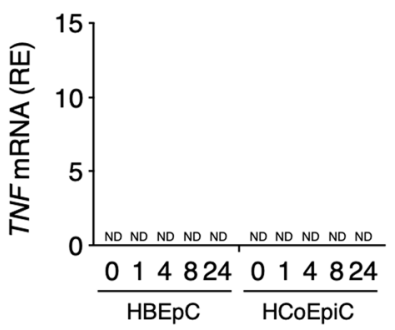

$\frac{014824}{\text { HBEpC }} \frac{014824}{\text { HCoEpiC }}$

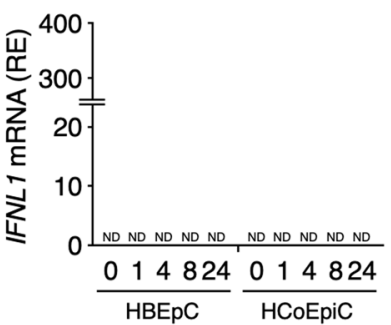

Extended Data Fig. 1 | ACE2 and TMPRSS2 expression levels in human lung cells. a, Quantitative RT-PCR analysis of ACE2 or TMPRSS2 mRNA in HPAEpiC, HBEpiC or A549 cells ( $n=3$ biologically independent samples). b, Copy number of viral RNA at $1 \mathrm{~h}$ after infection with SARS-CoV-2 or FluV in HPAEpiC, HBEpiC or A549 cells ( $n=3$ biologically independent samples) and the levels of SARS-CoV-2 RNA were not changed or rather higher than that of FluV RNA. c, Quantitative RT-PCR analysis of IFNB1, IFNL1, CXCL10, IL6 or TNF mRNA induction at 0, 1, 4, 8 or $24 \mathrm{~h}$ after infection with SARS-CoV-2 in $\mathrm{HBEpC}$ or HCoEpiC ( $n=3$ biologically independent samples). d, Copy number of SARS-CoV-2 RNA at $0,1,4,8$ or $24 \mathrm{~h}$ after infection with SARS-CoV-2 in $\mathrm{HBEpC}$ or HCoEpiC ( $n=3$ biologically independent samples). Colonic epithelial cells as well as lung epithelial cells are also known to be targeted by SARS-CoV-2. Data are presented as the mean values \pm s.d. and are representative of at least two independent experiments with similar results. RE, relative expression. ND, not detected. 


\section{NATURE IMMUNOLOGY}

a

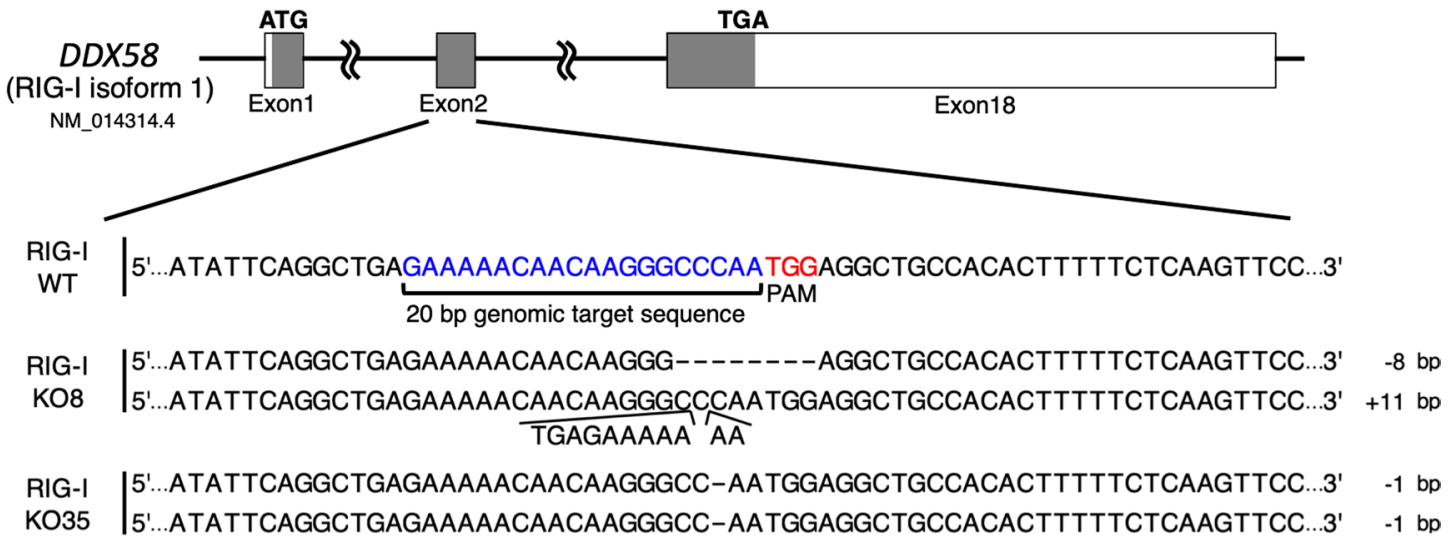

b

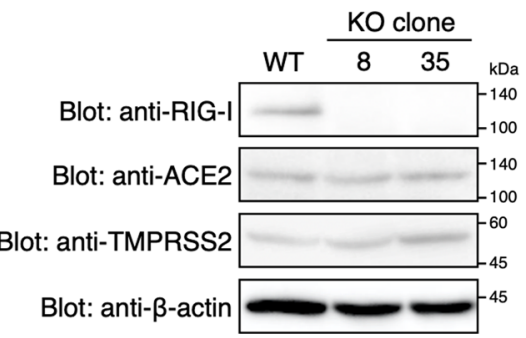

Extended Data Fig. 2 | Generation of RIG-I knockout A549 cells. a, Generation of RIG-I KO A549 cells. Schematic depiction of DDX58 locus. The grey boxes indicate RIG-I open reading frame (ORF). The start codon (ATG) and stop codon (TGA) of ORF are shown in bold. The 20 bp genomic sequence targeted by the single guide RNA (sgRNA) is indicated by blue letters. The protospacer-adjacent motif (PAM) sequence is depicted in red. The sizes of the insertion (+) or deletion (-) are indicated to the right of each mutated allele. The deleted nucleotide is indicated as hyphen. $\mathbf{b}$, Immunoblot analysis of RIG-I, ACE2 or TMPRSS2 in A549 RIG-I KO8 and KO35 cells. Data are representative of at least two independent experiments with similar results. 
a

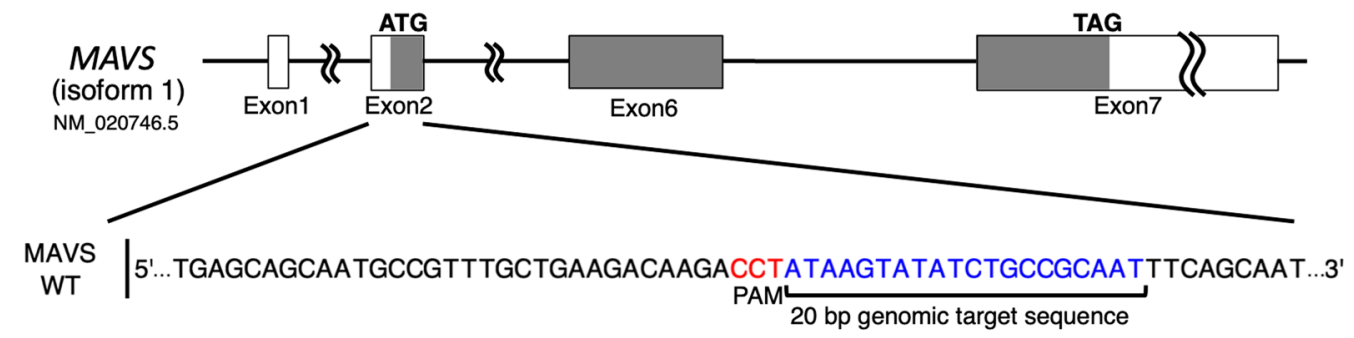

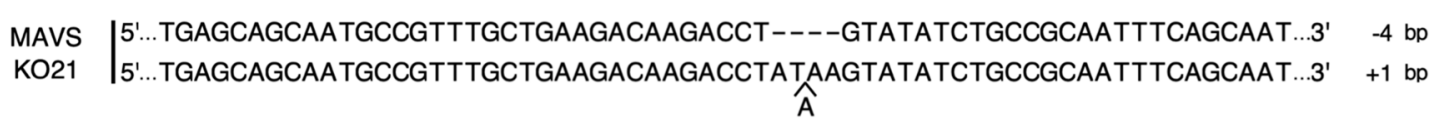

MAVS $\mid 5^{\prime} .$. TGAGCAGCAATGCCGTTTGCTGAAGACAAGACCT--AAGTATATCTGCCGCAATTTCAGCAAT...3' $\quad-2$ bp KO29 5'...TGAGCAGCAATGCCGTTTGCTGAAGACAAGACCTATAAGTATATCTGCCGCAATTTCAGCAAT...3' +1 bp

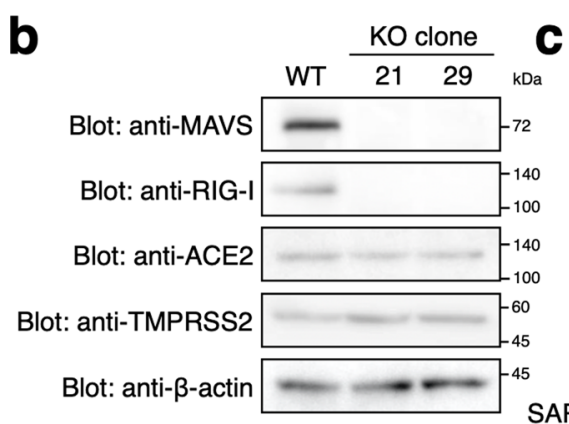

e

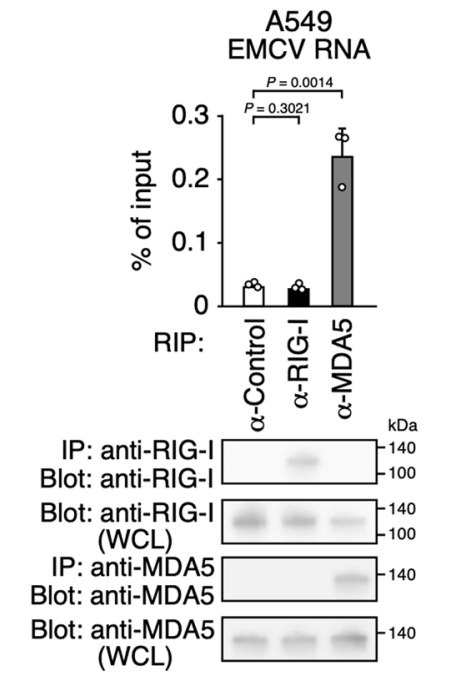

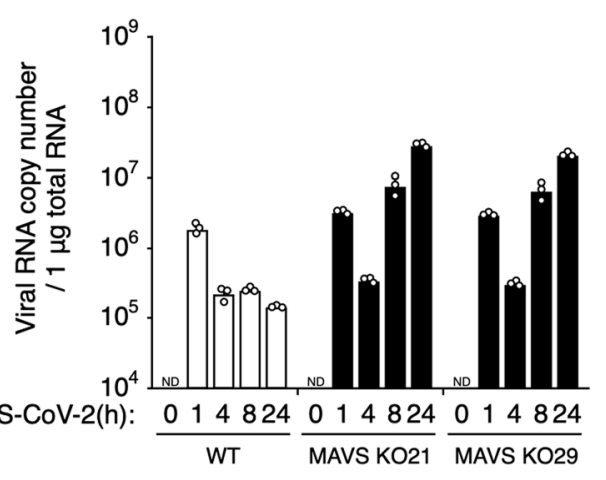

f

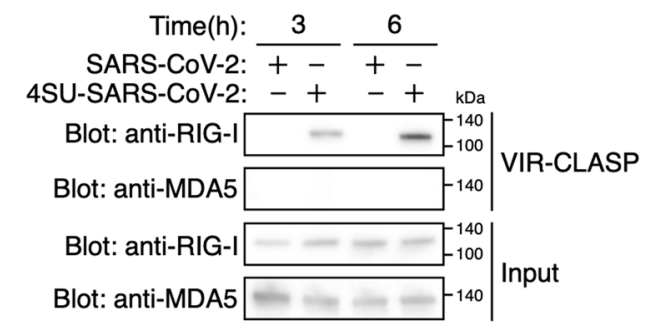

d

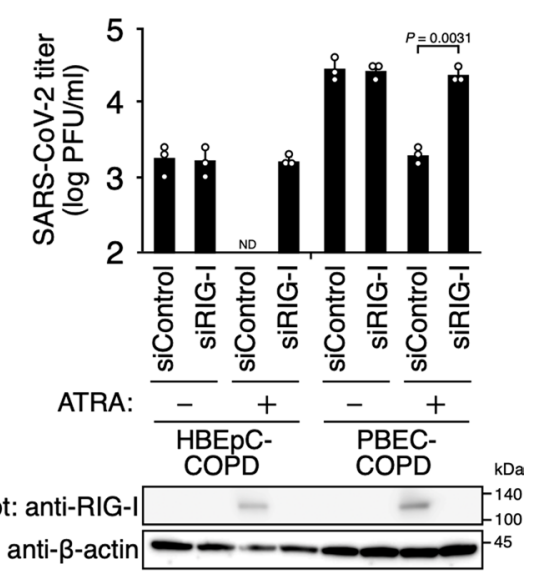

Extended Data Fig. 3 | See next page for caption. 
Extended Data Fig. 3 | Generation of MAVS knockout A549 cells. a, Generation of MAVS KO A549 cells. Schematic depiction of the MAVS locus. The grey boxes indicate MAVS ORF. The start codon (ATG) and stop codon (TAG) of ORF are shown in bold. The 20 bp genomic sequence targeted by the sgRNA is indicated by blue letters. The PAM sequence is depicted in red. The sizes of the insertion ( + ) or deletion (-) are indicated to the right of each mutated allele. The deleted nucleotide is indicated as hyphen. $\mathbf{b}$, Immunoblot analysis of MAVS, RIG-I, ACE2 or TMPRSS2 in A549 MAVS KO21 and KO29 cells. c, Copy number of SARS-CoV-2 RNA at 0, 1, 4, 8 or $24 \mathrm{~h}$ after infection with SARS-CoV-2 in A549 WT, MAVS KO21 and KO29 cells ( $n=3$ biologically independent samples). d, Viral titers at $5 \mathrm{~d}$ after infection with SARS-CoV-2 in HBEpC-COPD or PBEC-COPD transfected with siRNAs against gene products of RIG-I (siRIG-I) and then pretreated with ATRA $(1 \mu \mathrm{M})$ for $24 \mathrm{~h}$ (upper). Immunoblot analysis of RIG-I with the lysates of HBEpC-COPD or PBEC-COPD transfected with siRIG-I and then pretreated with ATRA $(1 \mu \mathrm{M})$ for $24 \mathrm{~h}$ (lower) ( $n=3$ biologically independent samples). e, RIP assay with A549 cell lysates prepared after $6 \mathrm{~h}$ of infection with EMCV by using anti-RIG-I, anti-MDA5. Immunoprecipitated EMCV RNA were quantitated by qRTPCR and were represented as fraction of input RNA prior to immunoprecipitation (percentage of input) (upper) ( $n=3$ biologically independent samples). Immunoblot analysis of whole cell lysate (WCL) and immunoprecipitated RIG-I or MDA5 (lower). f, Immunoblot analysis of RIG-I or MDA5 purified using VIR-CLASP from A549 cells infected with unlabeled or 4SU-labeled SARS-CoV-2 for 3 or $6 \mathrm{~h}$. Data are presented as the mean values \pm s.d. and are representative of at least two independent experiments with similar results. Statistical significance was determined by two-tailed Student's $t$-test. ND, not detected. 
a

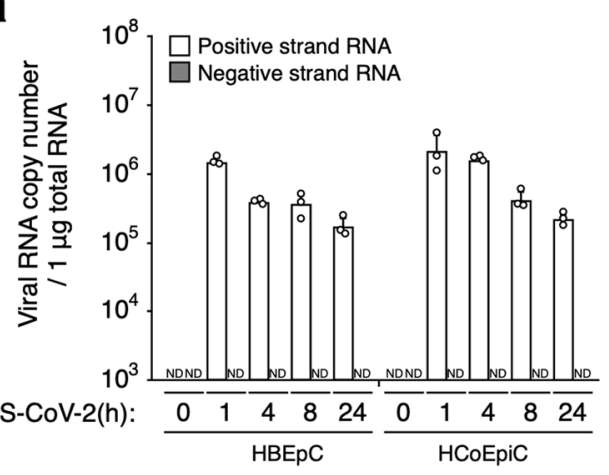

e
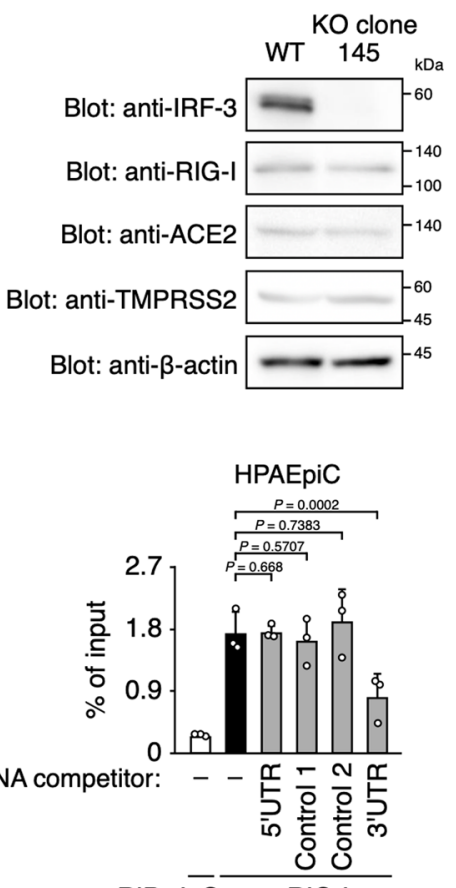

RIP: IgG $\alpha$-RIG-I b

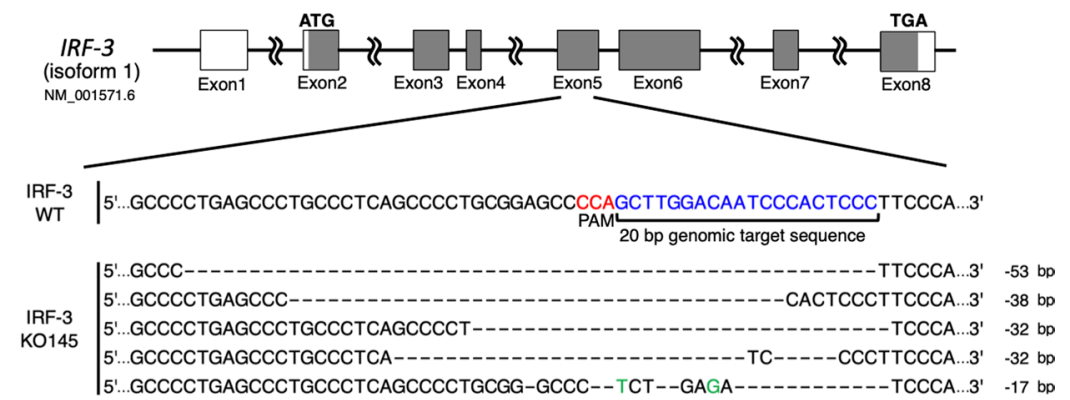

d

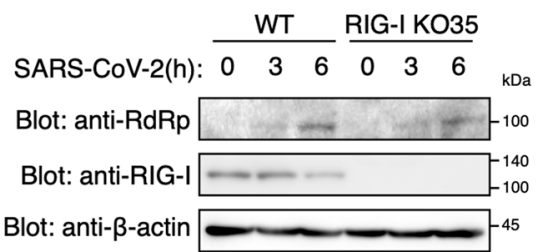

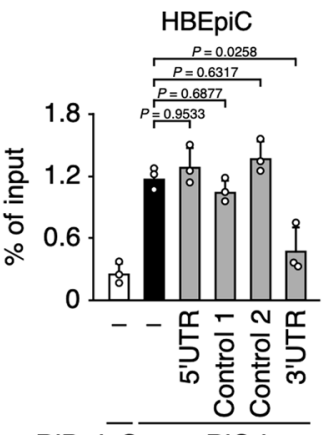

RIP: $\lg \quad \alpha-R I G-I$

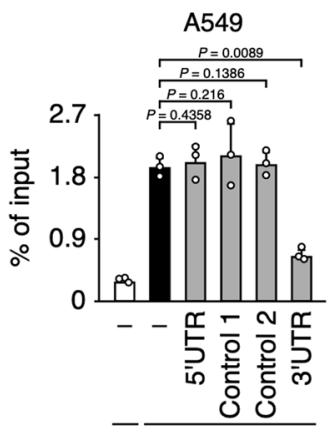

RIP: $\lg G \quad \alpha-R \mid G-I$ IP: anti-RIG-I

Extended Data Fig. 4 | RIG-I expression does not affect virus-induced RdRp expression after SARS-CoV-2 infection. a, Copy number of SARS-CoV-2 positive- or negative-strand RNA at $0,1,4,8$ or $24 \mathrm{~h}$ after infection with SARS-CoV-2 in HBEpC or HCoEpiC ( $n=3$ biologically independent samples). b, Generation of IRF-3 KO A549 cells. Schematic depiction of the IRF-3 locus. The grey boxes indicate IRF-3 open reading frame (ORF). The start codon (ATG) and stop codon (TGA) of ORF are shown in bold. The 20 bp genomic sequence targeted by the single guide RNA (sgRNA) is indicated by blue letters. The protospacer-adjacent motif (PAM) sequence is depicted in red. The sizes of the deletion (-) are indicated to the right of each mutated allele. The inserted nucleotides are indicated in green and the deleted nucleotide is indicated as hyphen. c, Immunoblot analysis of IRF-3, RIG-I, ACE2 or TMPRSS2 in A549 IRF-3 KO145 cells. d, Immunoblot analysis of RdRp in A549 WT or RIG-I KO35 cells infected with SARS-CoV-2 for 0, 3 or 6 h. e, HPAEpiC, HBEpiC or A549 cell lysates prepared after $6 \mathrm{~h}$ of infection with SARS-CoV-2 were incubated with the indicated in vitro-transcribed (IVT) RNAs. The interaction of SARS-CoV-2 positive-strand RNA and RIG-I was analyzed by RIP assay and qRT-PCR and were represented as fraction of input RNA prior to immunoprecipitation (percentage of input) (upper) ( $n=3$ biologically independent samples). Immunoblot analysis of immunoprecipitated amounts of RIG-I (lower). Data are presented as the mean values \pm s.d. and are representative of at least two independent experiments with similar results. Statistical significance was determined by two-tailed Student's $t$-test. ND, not detected. 
a

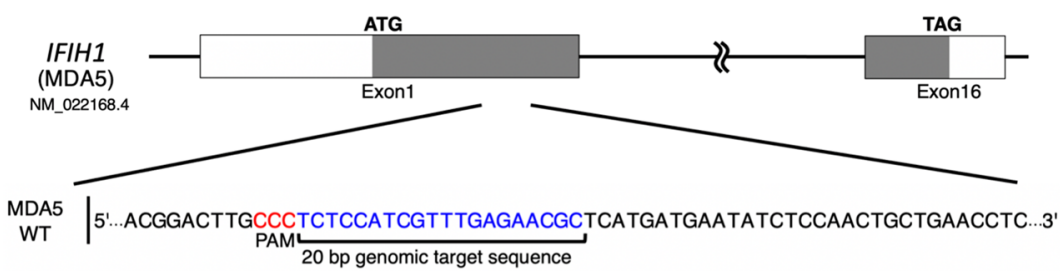

MDA5 $\mid 5^{\prime}$...ACGGACTTGCCCTCT--ATCGTTTGAGAACGCTCATGATGAATATCTCСАACTGCTGAACCTC ...3' $\quad-2$ bp KO9 5 '...ACGGACTTGCCCTCTCCATCGTTTGAGAACGCTCATGATGAATATCTCСАACTGCTGAACCTC.... $3^{\prime}+1$ bp $\hat{A}$

MDA5 $\mid 5^{\prime} \ldots$ ACGGACTTGCCCTC--CATCGTTTGAGAACGCTCATGATGAATATCTCCAACTGCTGAACCTC...3' $\quad-2$ bp KO21 5'...ACGGACTTGCССTCT-----GTTTGAGAACGCTCATGATGAATATCTCСААСTGCTGAACСTC...3' b

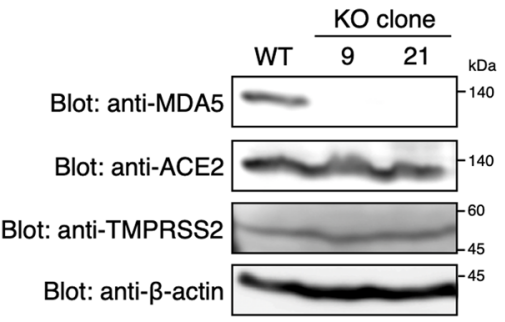

C

A549

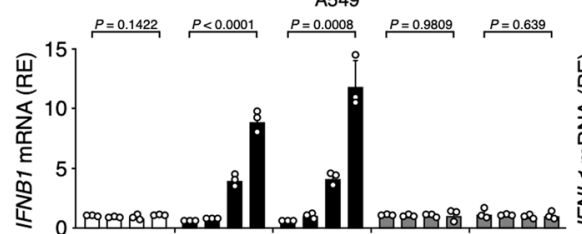

SARS-CoV-2(h): 082496082496082496082496082496

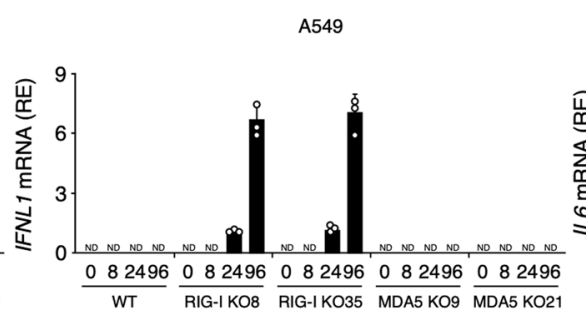

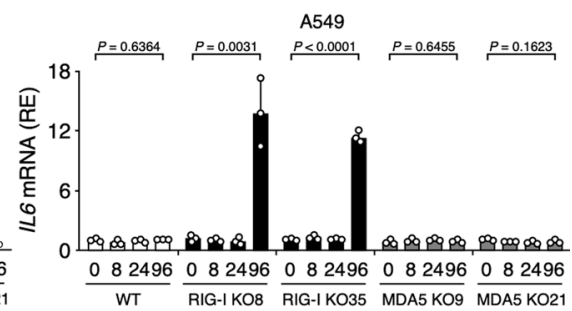

d

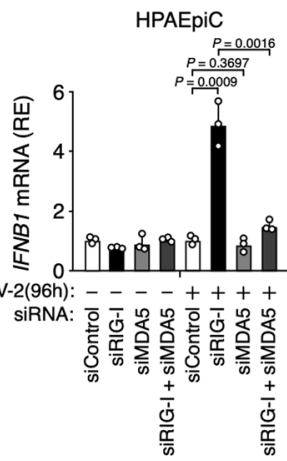

$\mathbf{f}$

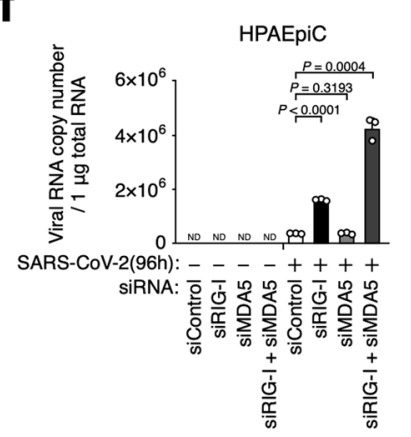

h

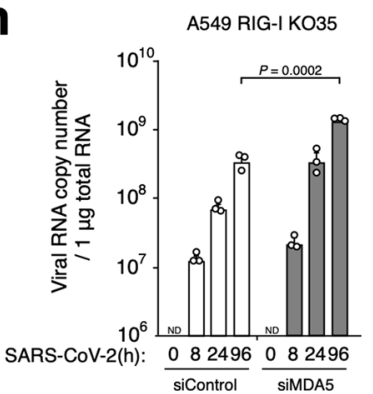

e
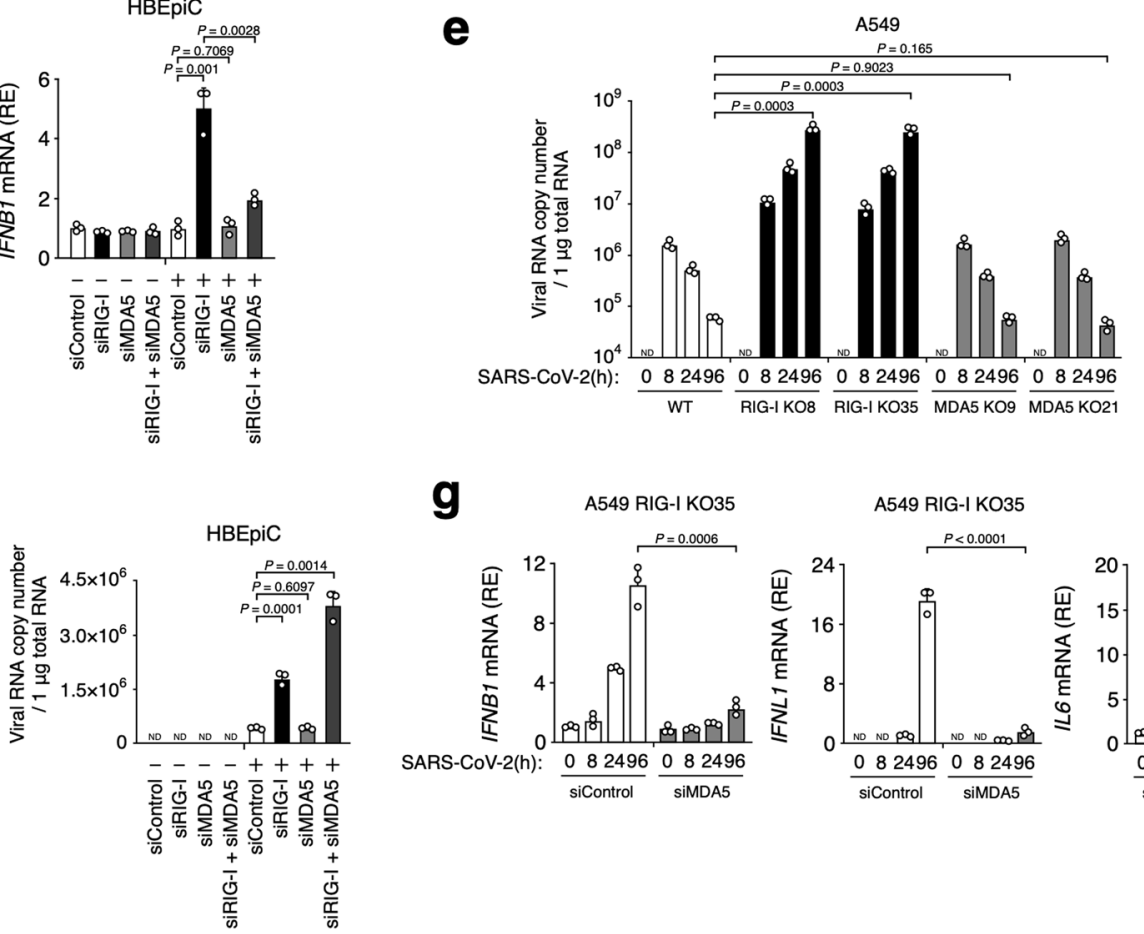

$\mathbf{g}$

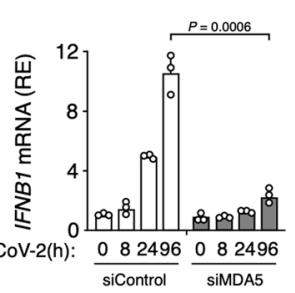

A549 RIG-I KO35

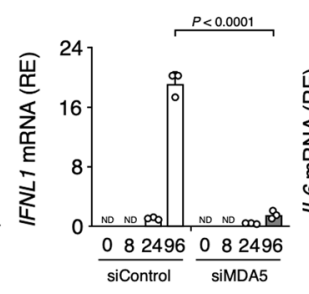

A549 RIG-I KO35

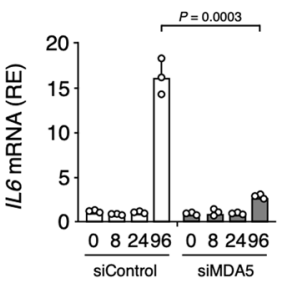

\section{Extended Data Fig. 5 | See next page for caption.}


Extended Data Fig. 5 | The profile of RNA sensor-mediated innate responses in A549 and primary human lung cells during SARS-CoV-2 infection.

a, Generation of MDA5 KO A549 cells. Schematic depiction of the IFIH1 locus. The grey boxes indicate MDA5 ORF. The start codon (ATG) and stop codon (TAG) of ORF are shown in bold. The $20 \mathrm{bp}$ genomic sequence targeted by the sgRNA is indicated by blue letters. The PAM sequence is depicted in red. The sizes of the insertion (+) or deletion (-) are indicated to the right of each mutated allele. The inserted nucleotides are indicated in green and the deleted nucleotide is indicated as hyphen. b, Immunoblot analysis of MDA5, ACE2 or TMPRSS2 in A549 MDA5 KO9 and KO21 cells. c, Quantitative RTPCR analysis of IFNB1, IFNL1 or IL6 mRNA induction at 0, 8, 24 or $96 \mathrm{~h}$ after infection with SARS-CoV-2 in A549 WT, RIG-I KO8, RIG-I KO35, MDA5 KO9 or MDA5 KO21 cells ( $n=3$ biologically independent samples). d, Quantitative RT-PCR analysis of IFNB1 mRNA induction at $96 \mathrm{~h}$ after infection with SARSCoV-2 in HPAEpiC (left) or HBEpiC (right) transfected with siRNAs against gene products of either RIG-I (siRIG-I) or MDA5 (siMDA5), or both ( $n=3$ biologically independent samples). e, Copy number of SARS-CoV-2 RNA at 0, 8, 24 or 96 h after infection with SARS-CoV-2 in A549 WT, RIG-I KO8, RIG-I KO35, MDA5 KO9 or MDA5 KO21 cells ( $n=3$ biologically independent samples). f, Copy number of SARS-CoV-2 RNA at $96 \mathrm{~h}$ after infection with SARSCoV-2 in HPAEpiC (left) or HBEpiC (right) transfected with siRIG-I or siMDA5, or both ( $n=3$ biologically independent samples). $\mathbf{g}$, Quantitative RT-PCR analysis of IFNB1, IFNL1 or IL6 mRNA induction at 0, 8, 24 or $96 \mathrm{~h}$ after infection with SARS-CoV-2 in A549 RIG-I KO35 cells transfected with siMDA5 ( $n=3$ biologically independent samples). h, Copy number of SARS-CoV-2 RNA at 0, 8, 24 or $96 \mathrm{~h}$ after infection with SARS-CoV-2 in A549 RIG-I KO35 cells transfected with siMDA5 ( $n=3$ biologically independent samples). Data are presented as the mean values \pm s.d. and are representative of at least two independent experiments with similar results. Statistical significance was determined by two-tailed Student's $t$-test. RE, relative expression. ND, not detected. 
a

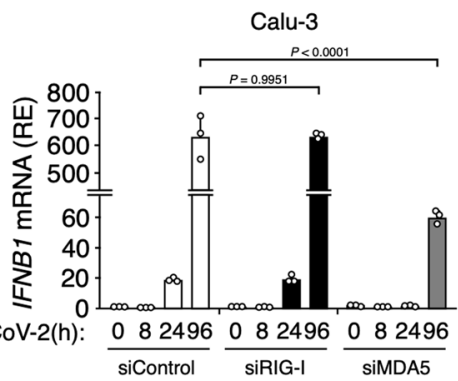

b

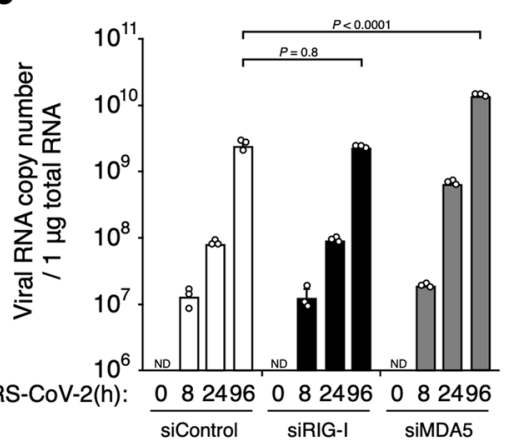

Calu-3

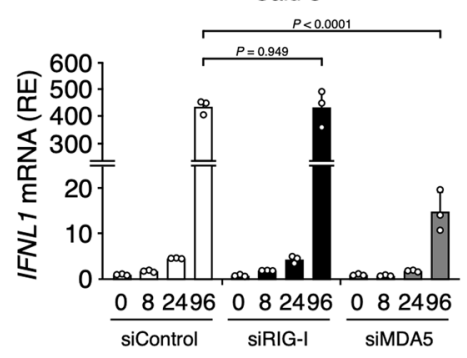

Calu-3

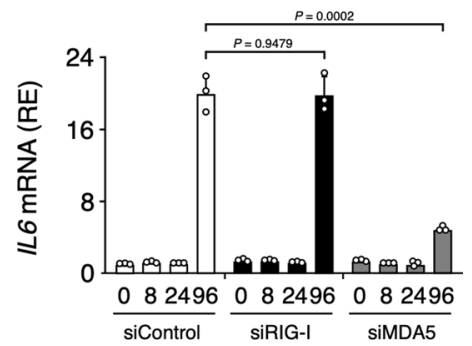

d
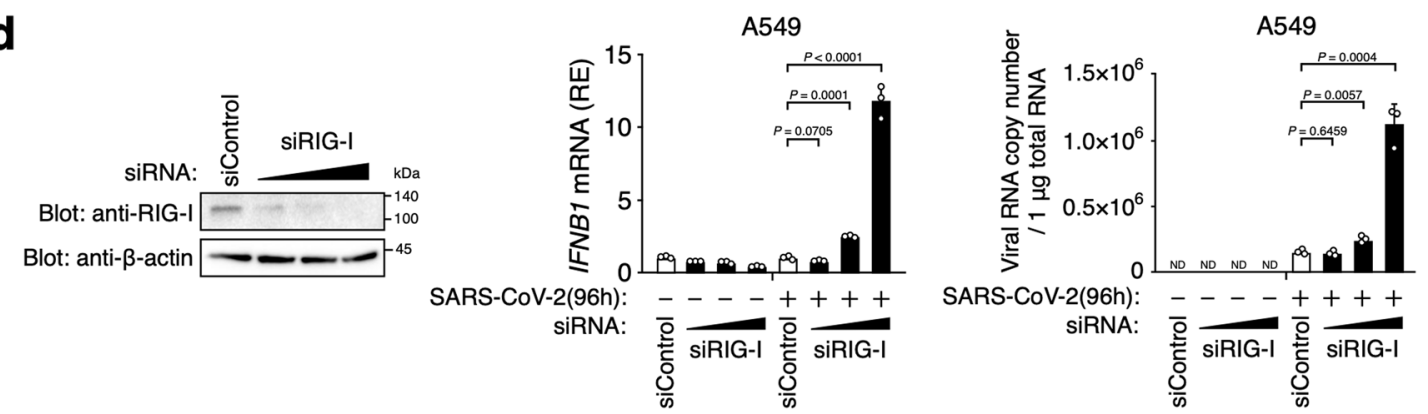

e

Calu-3

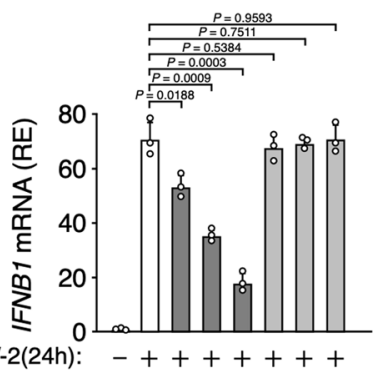

SARS-CoV-2(24h):
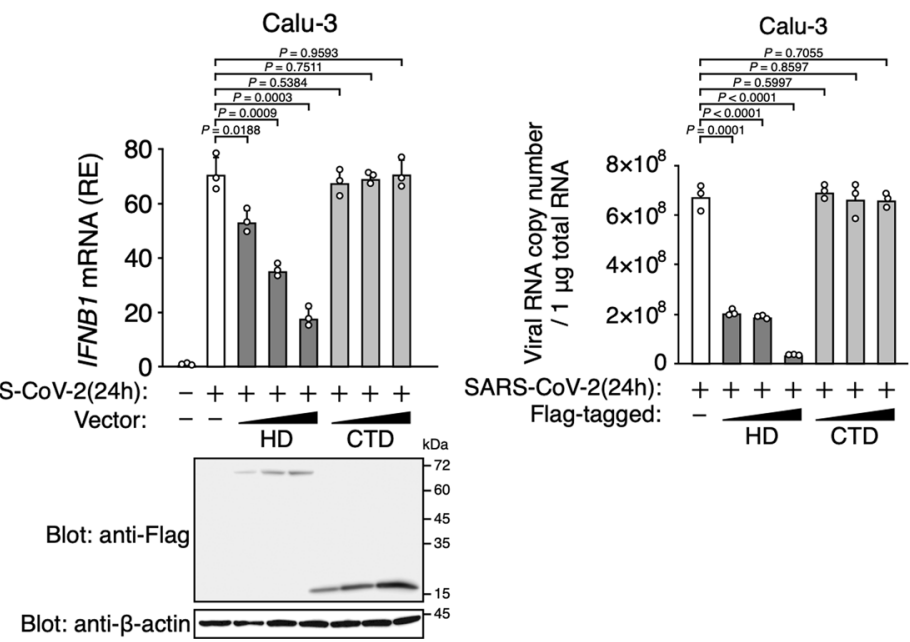

Extended Data Fig. 6 | See next page for caption. 
Extended Data Fig. 6 | The profile of RNA sensor-mediated innate responses in Calu-3 cells during SARS-CoV-2 infection. a, Quantitative RT-PCR analysis of IFNB1, IFNL1 or IL6 mRNA induction at $0,8,24$ or $96 \mathrm{~h}$ after infection with SARS-CoV-2 in Calu-3 cells transfected with siRNAs against gene products of RIG-I (siRIG-I) or MDA5 (siMDA5) ( $n=3$ biologically independent samples). b, Copy number of SARS-CoV-2 RNA at 0, 8,24 or $96 \mathrm{~h}$ after infection with SARS-CoV-2 in Calu-3 cells transfected with siRIG-I or MDA5 siMDA5 ( $n=3$ biologically independent samples). c, Immunoblot analysis of RIG-I, ACE2 or TMPRSS2 in HPAEpiC, HBEpiC, A549 or Calu-3 cells. d, Immunoblot analysis of RIG-I in A549 cells transfected with siRIG-I (0.5, 5 or $50 \mathrm{nM}$ ) (left). The siRNA-transfected A549 cells were infected with SARS-CoV-2 and at $96 \mathrm{~h}$ later, IFNB1 mRNA induction (middle) or copy number of SARS-CoV-2 RNA (right) were measured by qRT-PCR ( $n=3$ biologically independent samples). e, Quantitative RT-PCR analysis of IFNB1 mRNA induction (left) and copy number of SARS-CoV-2 RNA (right) at $24 \mathrm{~h}$ after infection with SARS-CoV-2 in Calu-3 cells transfected with empty vector (-) or Flag-tagged deletion mutants of RIG-I expression vector (upper) ( $n=3$ biologically independent samples). Immunoblot analysis of Flag-tagged deletion mutants of RIG-I (lower). Data are presented as the mean values \pm s.d. and are representative of at least two independent experiments with similar results. Statistical significance was determined by two-tailed Student's $t$-test. RE, relative expression. ND, not detected. 
a

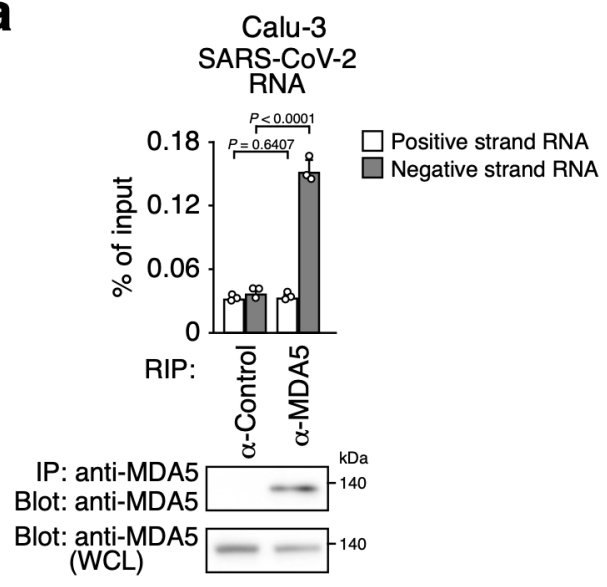

b

\section{A549 RIG-I KO35 \\ SARS-CoV-2 \\ RNA}

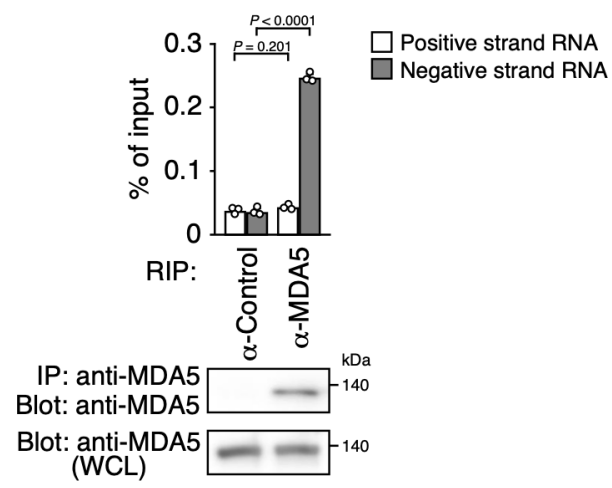

Extended Data Fig. 7 | MDA5 interacts with negative strand RNA of SARS-CoV-2 in Calu-3 and A549 RIG-I KO cells. a, RIP assay with Calu-3 cell lysates prepared after $24 \mathrm{~h}$ of infection with SARS-CoV-2 by using anti-MDA5 or control immunoglobulin. Immunoprecipitated SARS-CoV-2 positive- or negative-strand RNAs were quantitated by qRT-PCR and were represented as fraction of input RNA prior to immunoprecipitation (percentage of input) (upper) ( $n=3$ biologically independent samples). Immunoblot analysis of whole cell lysate (WCL) and immunoprecipitated amounts of MDA5 (lower). b, RIP assay with A549 RIG-I KO35 cell lysates prepared after $24 \mathrm{~h}$ of infection with SARS-CoV-2 by using anti-MDA5 or control immunoglobulin. Immunoprecipitated SARS-CoV-2 positive- or negative-strand RNAs were quantitated by qRT-PCR and were represented as fraction of input RNA prior to immunoprecipitation (percentage of input) (upper) ( $n=3$ biologically independent samples). Immunoblot analysis of WCL and immunoprecipitated amounts of MDA5 (lower). Data are presented as the mean values \pm s.d. and are representative of at least two independent experiments with similar results. Statistical significance was determined by two-tailed Student's $t$-test. 
a

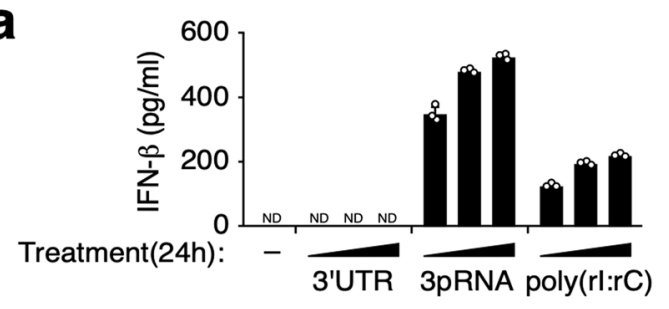

b IRIG-I(WT):

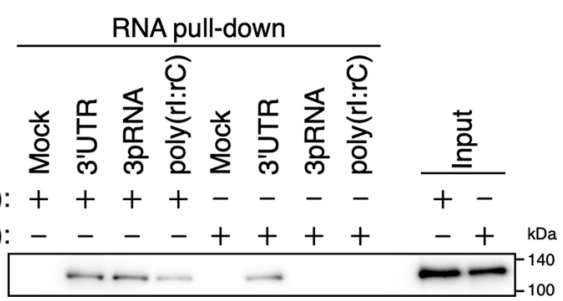

Extended Data Fig. 8 | 3'UTR of SARS-CoV-2 fails to induce IFN response and its interaction with RIG-I does not require the CTD-dependent RNA binding activity. $\mathbf{a}$, IFN- $\beta$ production by $3^{\prime} \mathrm{UTR}$, 3pRNA or poly $(\mathrm{rl}: \mathrm{rC}$ ) for $24 \mathrm{~h}$ in A549 cells ( $n=3$ biologically independent samples). b, RNA pull-down assay showing the binding activity of 3'UTR, 3pRNA or poly(rl:rC) to rRIG-I(WT) or rRIG-I(K888E). RIG-I K888E mutation, which is located in CTD, shows no RNA-binding activity to conventional RIG-I ligands. Data are presented as the mean values \pm s.d. and are representative of at least two independent experiments with similar results. ND, not detected. 


\section{Reporting Summary}

Nature Research wishes to improve the reproducibility of the work that we publish. This form provides structure for consistency and transparency in reporting. For further information on Nature Research policies, see our Editorial Policies and the Editorial Policy Checklist.

\section{Statistics}

For all statistical analyses, confirm that the following items are present in the figure legend, table legend, main text, or Methods section.

$\mathrm{n} / \mathrm{a}$ Confirmed

$\bigotimes$ The exact sample size $(n)$ for each experimental group/condition, given as a discrete number and unit of measurement

$\bigotimes$ A statement on whether measurements were taken from distinct samples or whether the same sample was measured repeatedly

The statistical test(s) used AND whether they are one- or two-sided

Only common tests should be described solely by name; describe more complex techniques in the Methods section.

$\bigotimes \square$ A description of all covariates tested

Х $\square$ A description of any assumptions or corrections, such as tests of normality and adjustment for multiple comparisons

$\triangle$ A full description of the statistical parameters including central tendency (e.g. means) or other basic estimates (e.g. regression coefficient)

AND variation (e.g. standard deviation) or associated estimates of uncertainty (e.g. confidence intervals)

For null hypothesis testing, the test statistic (e.g. $F, t, r$ ) with confidence intervals, effect sizes, degrees of freedom and $P$ value noted Give $P$ values as exact values whenever suitable.

Х $\square$ For Bayesian analysis, information on the choice of priors and Markov chain Monte Carlo settings

$\bigotimes \square$ For hierarchical and complex designs, identification of the appropriate level for tests and full reporting of outcomes

$\bigotimes \square$ Estimates of effect sizes (e.g. Cohen's $d$, Pearson's $r$ ), indicating how they were calculated

\section{Our web collection on statistics for biologists contains articles on many of the points above.}

\section{Software and code}

Policy information about availability of computer code

Data collection StepOne Software v2.3, Amersham Imager 680, IX-81S confocal microscope, CRISPRdirect program and M-folds software were used for qRTPCR analysis, immunoblotting, fluorescence analysis, single guide RNA sequence design and RNA secondary structure design, respectively.

Data analysis Mirosoft Excel (v16.3) was used to analysis data of qRT-PCR.

For manuscripts utilizing custom algorithms or software that are central to the research but not yet described in published literature, software must be made available to editors and

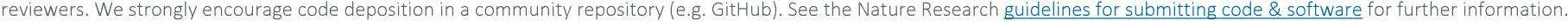

\section{Data}

Policy information about availability of data

All manuscripts must include a data availability statement. This statement should provide the following information, where applicable:

- Accession codes, unique identifiers, or web links for publicly available datasets

- A list of figures that have associated raw data

- A description of any restrictions on data availability

The data that support the findings of this study are available from the corresponding author upon reasonable request. Source data are provided with this paper. 
Please select the one below that is the best fit for your research. If you are not sure, read the appropriate sections before making your selection.

\ Life sciences

Behavioural \& social sciences Ecological, evolutionary \& environmental sciences

For a reference copy of the document with all sections, see nature.com/documents/nr-reporting-summary-flat.pdf

\section{Life sciences study design}

All studies must disclose on these points even when the disclosure is negative.

\begin{tabular}{|c|c|}
\hline Sample size & $\begin{array}{l}\text { No sample size calculation was performed. A minimum of three biologically independent samples were tested based on previous studies, and } \\
\text { experiments were conducted in at least two independent instances with similar results. }\end{array}$ \\
\hline Data exclusions & No data were excluded from analysis. \\
\hline Replication & We have repeated each experiment at least twice to ensure consistent results. All repeats performed showed similar trends. \\
\hline Randomization & For fluorescence analysis, the area were randomly selected. \\
\hline Blinding & $\begin{array}{l}\text { Blinding was not implemented in this study. Data were analyzed by software with objective outcomes and hence blinding was not } r \\
\text { this study. Quantification was performed in a uniform manner of all samples analyzed. }\end{array}$ \\
\hline
\end{tabular}

\section{Reporting for specific materials, systems and methods}

We require information from authors about some types of materials, experimental systems and methods used in many studies. Here, indicate whether each material, system or method listed is relevant to your study. If you are not sure if a list item applies to your research, read the appropriate section before selecting a response.

\begin{tabular}{|c|c|c|}
\hline \multicolumn{2}{|r|}{ Materials \& experimental systems } & Methods \\
\hline $\mathrm{n} / \mathrm{a}$ & Involved in the study & $\mathrm{n} / \mathrm{a}$ Involved in the study \\
\hline${ }^{-}$ & $\bigotimes$ Antibodies & $X \square$ ChIP-seq \\
\hline L & $\bigotimes$ Eukaryotic cell lines & $\triangle \square$ Flow cytometry \\
\hline$\bigotimes$ & $\square$ Palaeontology and archaeology & $\bigotimes \mid \square$ MRI-based neuroimaging \\
\hline$\bigotimes$ & $\square$ Animals and other organisms & \\
\hline Х & $\square$ Human research participants & \\
\hline Х & $\square$ Clinical data & \\
\hline Х & $\square$ Dual use research of concern & \\
\hline
\end{tabular}

\section{Antibodies}

Antibodies used

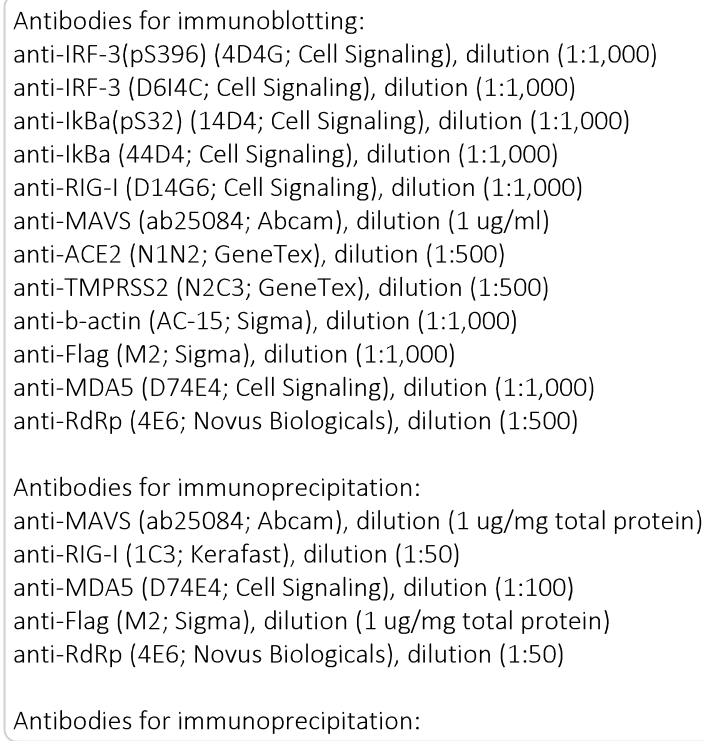


anti-Spike (1A9; GeneTex), dilution (1:100)

goat anti-Mouse IgG secondary antibody conjugated to Alexa Fluor 488 (A11029; Molecular Probes), dilution (2 ug/ml)

Validation

All the antibodies used in this studies were purchased from commercial vendors. Validation of antibodies used in this study is described in technical data sheets provided by manufacturers websites. As for anti-RdRp (4E6; Novus Biologicals) antibodies, this antibody was originally developed for detection of SARS coronavirus replicase, which has $96 \%$ homology with SARS-CoV-2 RdRp. This anti-RdRp (4E6; Novus Biologicals) antibodies were validated for specificity by using SARS-CoV-2 infection experiment presented in Extended Data Fig. $4 \mathrm{~d}$ of the manuscript.

\section{Eukaryotic cell lines}

Policy information about cell lines

Cell line source(s)

A549 cells (CCL-185), Vero E6 cells (CRL-1586), Calu-3 cells (HTB-55), HEK293T cells (CRL-3216), Vero cells (CCL-81), MadinDarby canine kidney (MDCK) (CCL-34), primary Bronchial/Tracheal Epithelial Cells; COPD (PBEC-COPD) (\#PCS-300-013) were obtained from American Type Culture Collection (ATCC). Sf9 cells (B82501) were purchased from invitrogen. Human Pulmonary Alveolar Epithelial Cells (HPAEpiC) (\#3200), Human Bronchial Epithelial Cells (HBEpiC) (\#3210) and Human Colonic Epithelial Cells (HCoEpiC) (\#2950) were purchased from ScienCell. Human Bronchial Epithelial Cells (HBEpC) (\#CA50205a) and HBEpC-COPD (\#CA502COPDK05a) were obtained from Cell Applications, Inc.

Authentication

Mycoplasma contamination

Commonly misidentified lines (See ICLAC register)
None of the cell lines used were authenticated.

All of cell lines are tested negative for mycoplasma contamination.

No commonly misidentified lines were used. 